\title{
Common fixed point theorems satisfying integral type rational contractive conditions and applications
}

\author{
H. K. Nashine
}




\title{
COMMON FIXED POINT THEOREMS SATISFYING INTEGRAL TYPE RATIONAL CONTRACTIVE CONDITIONS AND APPLICATIONS
}

\author{
H. K. NASHINE \\ Received 15 February, 2014
}

\begin{abstract}
Inspired by the concept of integral type (Branciari type) contractive condition and respective fixed point results, we derive some new common fixed point theorems for quadruple self mappings satisfying a generalized $\mathcal{W}$-contractive condition or a generalized $\phi$-contractive condition of integral type, also using the notions of compatibility and subsequential continuity (alternately subcompatibility and reciprocal continuity) in the frame of metric spaces. We furnish some examples to illustrate the useability of our main results. Several results existing in the literature are obtained as consequences of the main results. At the end of this article the existence and uniqueness of solutions for certain systems of integral equations and functional equations arising in dynamic programming are demonstrated with the help of the obtained results.
\end{abstract}

2010 Mathematics Subject Classification: 47H10; 54H25

Keywords: metric space, compatible mappings, reciprocal continuity, subcompatible mappings, subsequential continuity, fixed point

\section{INTRODUCTION}

The Banach Contraction Principle is a very popular tools which is used to solve existence problems in many branches of Mathematical Analysis and its applications. It is no surprise that there is a great number of generalizations of this fundamental theorem. They go in several directions-modifying the basic contractive condition or changing the ambiental space. This celebrated theorem can be stated as follows.

Theorem 1 ([12]). Let $(X, d)$ be a complete metric space and $T$ be a mapping of $X$ into itself satisfying:

$$
d(T x, T y) \leq k d(x, y), \forall x, y \in X,
$$

where $k$ is a constant in $(0,1)$. Then, $T$ has a unique fixed point $x^{*} \in X$.

Banach Contraction Principle provides a technique for solving a variety of applied problems in mathematical sciences and engineering. Later, many authors have extended, generalized and improved Banach fixed point theorem in different ways (see $[22-26,40,47])$. 
During the late 20th century, metrical common fixed point theory saw a trend of investigation which moved around commuting nature of two maps. Several conditions were introduced, including weak commutativity (Sessa [52]), compatibility (Jungck [33]), weak compatibility (Jungck and Rhoades [34]) and many others, and a lot of respective common fixed point results were obtained. A survey of these notions and relationship among them can be seen in [35].

We recall that two mappings $A, S: X \rightarrow X$ are called weakly compatible if they commute at their coincidence points, that is, $A S x=S A x$ whenever $A x=S x$.

In the study of common fixed points of compatible-type mappings we often require assumption of completeness of the space or continuity of mappings involved besides some contractive condition, but the study of common fixed points of noncompatible mappings can be extended to the class of non-expansive or Lipschitz type mapping pairs even without assuming the continuity of the mappings involved or the completeness of the space. Aamri and El Moutawakil [1] generalized the concept of non-compatibility by defining the notion of (E.A) property and proved common fixed point theorems under strict contractive conditions. Although (E.A) property is a generalization of the concept of non-compatible maps, yet it requires either completeness of the whole space or some of the range spaces or continuity of maps. After that, Liu et al. [37] defined the notion of common property (E.A) for a hybrid pair of single- and multi-valued mappings and proved some fixed point results under hybrid contractive conditions.

Further, Al-Thagafi and Shahzad [3] introduced the notion of occasionally weakly compatible mappings which is the most general among all the commutativity concepts. However, in an interesting note, Djorić et al. [27] observed that the condition of occasionally weak compatibility reduces to weak compatibility in the presence of a unique point of coincidence (or a unique common fixed point) of the given pair of mappings. Thus, no generalization can be obtained by replacing weak compatibility with occasionally weak compatibility. In 2009 Bouhadjera and Godet-Thobie [17] further enlarged the class of compatible (reciprocally continuous) pairs by introducing the concept of subcompatible (subsequential continuous) pair which is substantially weaker than using compatibility (reciprocal continuity). Since then, Imdad et al. [31], as well as Chauhan et al. [21] improved the results of [17] and showed that these results can easily be recovered by replacing subcompatibility with compatibility or subsequential continuity with reciprocal continuity.

On the other hand, Branciari [19] obtained a fixed point result for a single mapping satisfying an analogue of Banach's contraction principle with an integral type inequality. This celebrated theorem can be stated as follow.

Theorem 2. Let $(X, d)$ be a complete metric space, $k \in(0,1)$, and let $f: X \rightarrow X$ be a mapping such that for each $x, y \in X$,

$$
\int_{0}^{d(f x, f y)} \varphi(t) d t \leq k \int_{0}^{d(x, y)} \varphi(t) d t
$$


where $\varphi: \mathbb{R}_{+} \rightarrow \mathbb{R}_{+}$is a Lebesgue-integrable function which is summable (i.e., with finite integral) on each compact subset of $[0,+\infty)$, non-negative and such that $\int_{0}^{\epsilon} \varphi(t) d t>0$, for each $\epsilon>0$. Then $f$ has a unique fixed point $a \in X$ such that for each $x \in X, \lim _{n \rightarrow \infty} f^{n} x=a$.

Later, some interesting and rich fixed point theorems involving more general contractive conditions of integral type were obtained in [2,5-11,28,48,50,51,53-55,57]. Recently, Chauhan et al. [20] studied integral type fixed point results for two pairs of mappings which are non-commutative and non-continuous, and gave applications to dynamic systems.

Inspired by the concept of integral type (Branciari type) conditions and notions of compatibility and subsequential continuity (alternately subcompatibility and reciprocal continuity), an attempt has been made in this article to prove fixed point theorems for two pairs of self mappings under a new type of contractive conditions, namely generalized $\mathcal{W}$-contractive condition and generalized $\phi$-contractive condition of integral type in the setting of metric spaces. Some examples are furnished to show validity of hypothesis of results in dissimilar circumstances. Several results existing in the literature are obtained as consequences of the main results. Our results improve and generalize several comparable results in the existing literature. We wrap up the paper with applications of our results to an existence result for certain system of integral equations and solvability of certain system of functional equations arising in dynamic programming.

\section{Preliminaries}

Throughout the paper, $\mathbb{N}$ is the set of positive integers. To start with, we state the following definitions.

Definition 1. Let $A, S: X \rightarrow X$ be two self mappings of a metric space $(X, d)$. The mappings $A$ and $S$ are said to be

(1) commuting if $A S x=S A x$, for all $x \in X$;

(2) weakly commuting [52] if $d(A S x, S A x) \leq d(A x, S x)$, for all $x \in X$;

(3) compatible [33] if $\lim _{n \rightarrow \infty} d\left(A S x_{n}, S A x_{n}\right)=0$ whenever there exists a sequence $\left\{x_{n}\right\}$ in $X$ such that $\lim _{n \rightarrow \infty} A x_{n}=\lim _{n \rightarrow \infty} S x_{n}=z$, for some $z \in X$;

(4) non-compatible [43] if there exists a sequence $\left\{x_{n}\right\}$ in $X$ such that $\lim _{n \rightarrow \infty} A x_{n}=$ $\lim _{n \rightarrow \infty} S x_{n}=z$, for some $z \in X$ and $\lim _{n \rightarrow \infty} d\left(A S x_{n}, S A x_{n}\right)$ is either nonzero or nonexistent;

(5) weakly compatible [34] if they commute at their coincidence points, i.e., $A S u=S A u$ whenever $A u=S u$, for some $u \in X$;

(6) occasionally weakly compatible [3] if and only if there is a point $x \in X$ which is a coincidence point of $A$ and $S$ at which $A$ and $S$ commute. 
Definition 2 ([41]). A pair $(A, S)$ of self mappings of a metric space $(X, d)$ is called reciprocally continuous if for a sequence $\left\{x_{n}\right\}$ in $X, \lim _{n \rightarrow \infty} A S x_{n}=A z$ and $\lim _{n \rightarrow \infty} S A x_{n}=S z$, whenever $\lim _{n \rightarrow \infty} A x_{n}=\lim _{n \rightarrow \infty} S x_{n}=z$, for some $z \in X$.

It is easy to see that if two self mappings are continuous, then they are obviously reciprocally continuous but the converse is not true [42, Example 2]. Moreover, in the setting of common fixed point theorems for compatible pairs of self mappings satisfying contractive conditions, continuity of one of the mappings implies their reciprocal continuity but not conversely (see [41]).

Definition 3 ([1]). A pair $(A, S)$ of self mappings of a metric space $(X, d)$ is said to satisfy the property (E.A) if there exist a sequence $\left\{x_{n}\right\}$ in $X$ and some $z \in X$ such that

$$
\lim _{n \rightarrow \infty} A x_{n}=\lim _{n \rightarrow \infty} S x_{n}=z \in X .
$$

It can be noticed that any non-compatible self mappings of a metric space $(X, d)$ satisfy the property (E.A) but two mappings satisfying the property (E.A) need not be non-compatible (see [29, Example 1]). Also, weak compatibility and the property (E.A) are independent to each other (see [44, Examples 2.1-2.2]).

Definition 4 ([4]). Two pairs $(A, S)$ and $(B, T)$ of self mappings of a metric space $(X, d)$ are said to satisfy the common property (E.A), if there exist two sequences $\left\{x_{n}\right\},\left\{y_{n}\right\}$ in $X$ for some $z$ in $X$ and such that

$$
\lim _{n \rightarrow \infty} A x_{n}=\lim _{n \rightarrow \infty} S x_{n}=\lim _{n \rightarrow \infty} T y_{n}=\lim _{n \rightarrow \infty} B y_{n}=z .
$$

Definition 5 ([17]). A pair $(A, S)$ of self mappings of a metric space $(X, d)$ is said to be subcompatible if there exists a sequence $\left\{x_{n}\right\}$ such that $\lim _{n \rightarrow \infty} A x_{n}=$ $\lim _{n \rightarrow \infty} S x_{n}=z$, for some $z \in X$ and $\lim _{n \rightarrow \infty} d\left(A S x_{n}, S A x_{n}\right)=0$.

A pair of non-compatible or subcompatible mapping satisfies the property (E.A). Obviously, compatible mappings which satisfy the property (E.A) are subcompatible but the converse statement does not hold in general (see [49, Example 2.3]). Two occasionally weakly compatible mappings are subcompatible, however the converse is not true in general (see [18, Example 1.2]).

Definition 6 ([17]). A pair $(A, S)$ of self mappings of a metric space $(X, d)$ is called subsequentially continuous if there exists a sequence $\left\{x_{n}\right\}$ in $X$ such that $\lim _{n \rightarrow \infty} A x_{n}=\lim _{n \rightarrow \infty} S x_{n}=z$, for some $z \in X$ and $\lim _{n \rightarrow \infty} A S x_{n}=A z$ and $\lim _{n \rightarrow \infty} S A x_{n}=$ $S z$.

One can easily check that if two self mappings are continuous or reciprocally continuous, then they are naturally subsequentially continuous. However, there exist subsequentially continuous pairs of mappings which are neither continuous nor reciprocally continuous (see [18, Example 1.4]). 


\section{COMMON FIXED POINT RESULTS UNDER $\mathcal{W}$-WEAKLY CONTRACTIVE CONDITION}

The attempted improvements in this section are five-fold.

(i) The condition on containment of ranges amongst the involved mappings is relaxed.

(ii) Continuity requirements of all the involved mappings are completely relaxed.

(iii) The (E.A) property is replaced by compatible and subsequentially continuous (alternately subcompatible and reciprocally continuous) property which are the most general among all existing weak commutativity concepts.

(iv) The condition on completeness of the whole space is relaxed.

(v) A generalized $\mathfrak{W}$-weakly contractiveness is taken into consideration to derive our results.

In what follows, we denote by $\Psi$ the collection of all functions $\mathcal{W}:[0, \infty) \rightarrow$ $[0, \infty)$ which are continuous and satisfy $\mathcal{W}(t)<t$, for all $t>0$.

Also, we will denote by $\Phi$ the set of functions $\varphi:[0,+\infty) \rightarrow[0,+\infty)$ satisfying the following conditions:

$\left(\varphi_{1}\right) \varphi$ is a Lebesgue integrable function on each compact subset of $[0,+\infty)$.

$\left(\varphi_{2}\right) \int_{0}^{\varepsilon} \varphi(s) d s>0$ for all $\varepsilon>0$.

In this section we state and prove the following theorem.

Theorem 3. Let $A, B, S, T: X \rightarrow X$ be four self mappings of a metric space $(X, d)$. If the pairs $(A, S)$ and $(B, T)$ are compatible and subsequentially continuous (alternately subcompatible and reciprocally continuous), then

(1) the pair $(A, S)$ has a coincidence point,

(2) the pair $(B, T)$ has a coincidence point.

For all $x, y \in X$, we define

$$
=\max \left\{\begin{array}{c}
\Theta(x, y) \\
d(A x, S x), d(B y, T y), d(T y, S x), \frac{1}{2}[d(A x, T y)+d(B y, S x)], \\
\frac{d(A x, S x) d(B y, T y)}{1+d(T y, S x)}, \frac{d(A x, T y) d(B y, S x)}{1+d(T y, S x)}, \frac{d(A x, T y) d(B y, S x)}{1+d(A x, B y)}
\end{array}\right\} .
$$

We assume that, for all $x, y \in X$,

$$
\int_{0}^{d(A x, B y)} \varphi(t) d t \leq \int_{0}^{\Theta(x, y)} \varphi(t) d t-\mathcal{W}\left(\int_{0}^{\Theta(x, y))} \varphi(t) d t\right),
$$

where $\mathcal{W} \in \Psi$ and $\varphi \in \Phi$. Then $A, B, S$ and $T$ have a unique common fixed point in $X$.

Proof. The proof of the theorem is divided into the following two parts: 
Part I: Since the pair $(A, S)$ (as well as $(B, T))$ is subsequentially continuous and compatible, therefore there exists a sequence $\left\{x_{n}\right\}$ in $X$ such that

$$
\lim _{n \rightarrow \infty} A x_{n}=\lim _{n \rightarrow \infty} S x_{n}=\zeta
$$

for some $\zeta \in X$, and

$$
\lim _{n \rightarrow \infty} d\left(A S x_{n}, S A x_{n}\right)=d(A \zeta, S \zeta)=0,
$$

with $A \zeta=S \zeta$, whereas in respect to the pair $(B, T)$, there exists a sequence $\left\{y_{n}\right\}$ in $X$ such that

$$
\lim _{n \rightarrow \infty} B y_{n}=\lim _{n \rightarrow \infty} T y_{n}=\xi
$$

for some $\xi \in X$, and

$$
\lim _{n \rightarrow \infty} d\left(B T y_{n}, T B y_{n}\right)=d(B \xi, T \xi)=0,
$$

with $B \xi=T \xi$. Hence $\zeta$ is a coincidence point of the pair $(A, S)$, and $\xi$ is a coincidence point of the pair $(B, T)$.

Now we prove that $\zeta=\xi$. By putting $x=x_{n}$ and $y=y_{n}$ in inequality (3.1), we have

$$
\int_{0}^{d\left(A x_{n}, B y_{n}\right)} \varphi(t) d t \leq \int_{0}^{\Theta\left(x_{n}, y_{n}\right)} \varphi(t) d t-\mathcal{W}\left(\int_{0}^{\Theta\left(x_{n}, y_{n}\right)} \varphi(t) d t\right)
$$

where

$$
\begin{gathered}
\Theta\left(x_{n}, y_{n}\right)=\max \\
\left\{\begin{array}{c}
d\left(A x_{n}, S x_{n}\right), d\left(B y_{n}, T y_{n}\right), d\left(T y_{n}, S x_{n}\right), \frac{1}{2}\left[d\left(A x_{n}, T y_{n}\right)+d\left(B y_{n}, S x_{n}\right)\right], \\
\frac{d\left(A x_{n}, S x_{n}\right) d\left(B y_{n}, T y_{n}\right)}{1+d\left(T y_{n}, S x_{n}\right)}, \frac{d\left(A x_{n}, T y_{n}\right) d\left(B y_{n}, S x_{n}\right)}{1+d\left(T y_{n}, S x_{n}\right)}, \frac{d\left(A x_{n}, T y_{n}\right) d\left(B y_{n}, S x_{n}\right)}{1+d\left(A x_{n}, B y_{n}\right)}
\end{array}\right\} .
\end{gathered}
$$

Passing to the limit as $n \rightarrow \infty$ in inequality (3.2), we have

$$
\int_{0}^{d(\zeta, \xi)} \varphi(t) d t \leq \int_{0}^{\Theta(\zeta, \xi)} \varphi(t) d t-\mathcal{W}\left(\int_{0}^{\Theta(\zeta, \xi)} \varphi(t) d t\right)
$$

where

$$
\Theta(\zeta, \xi)=\max \left\{d(\zeta, \xi), d(\zeta, \xi), d(\zeta, \xi), \frac{d^{2}(\zeta, \xi)}{1+d(\zeta, \xi)}, \frac{d^{2}(\zeta, \xi)}{1+d(\zeta, \xi)}\right\}=d(\zeta, \xi) .
$$

Therefore

$$
\int_{0}^{d(\zeta, \xi)} \varphi(t) d t \leq \int_{0}^{d(\zeta, \xi)} \varphi(t) d t-\mathcal{W}\left(\int_{0}^{d(\zeta, \xi)} \varphi(t) d t\right)<\int_{0}^{d(\zeta, \xi)} \varphi(t) d t
$$


which is a contradiction. Thus, we have $\zeta=\xi$. Now we assert that $A \zeta=\zeta$. Putting $x=\zeta$ and $y=y_{n}$ in inequality (3.1), we get

$$
\int_{0}^{d\left(A \zeta, B y_{n}\right)} \varphi(t) d t \leq \int_{0}^{\Theta\left(\zeta, y_{n}\right)} \varphi(t) d t-\mathcal{W}\left(\int_{0}^{\Theta\left(\zeta, y_{n}\right)} \varphi(t) d t\right)
$$

where

$$
=\max \left\{\begin{array}{c}
\Theta\left(\zeta, y_{n}\right) \\
d(A \zeta, S \zeta), d\left(B y_{n}, T y_{n}\right), d\left(T y_{n}, S \zeta\right), \frac{1}{2}\left[d\left(A \zeta, T y_{n}\right)+d\left(B y_{n}, S \zeta\right)\right], \\
\frac{d(A \zeta, S \zeta) d\left(B y_{n}, T y_{n}\right)}{1+d\left(T y_{n}, S \zeta\right)}, \frac{d\left(A \zeta, T y_{n}\right) d\left(B y_{n}, S \zeta\right)}{1+d\left(T y_{n}, S \zeta\right)}, \frac{d\left(A \zeta, T y_{n}\right) d\left(B y_{n}, S \zeta\right)}{1+d\left(A \zeta, B y_{n}\right)}
\end{array}\right\} .
$$

Passing to the limit as $n \rightarrow \infty$ in condition (3.3), we obtain

$$
\int_{0}^{d(A \zeta, \xi)} \varphi(t) d t \leq \int_{0}^{\Theta(\zeta, \xi)} \varphi(t) d t-\mathcal{W}\left(\int_{0}^{\Theta(\zeta, \xi)} \varphi(t) d t\right)
$$

where

$$
\Theta(\zeta, \xi)=\max \left\{d(\xi, A \zeta), d(A \zeta, \xi), \frac{d^{2}(A \zeta, \xi)}{1+d(\xi, A \zeta)}, \frac{d^{2}(A \zeta, \xi)}{1+d(A \zeta, \xi)}\right\}=d(A \zeta, \xi) .
$$

Therefore we get

$$
\int_{0}^{d(A \zeta, \zeta)} \varphi(t) d t \leq \int_{0}^{d(A z, z)} \varphi(t) d t-\mathcal{W}\left(\int_{0}^{d(A z, z)} \varphi(t) d t\right)<\int_{0}^{d(A \zeta, \zeta)} \varphi(t) d t,
$$

which is a contradiction. Thus, we have $A \zeta=\zeta$. Therefore, $A \zeta=S \zeta=\zeta$.

Now we show that $B \zeta=\zeta$. Putting $x=x_{n}$ and $y=\zeta$ in inequality (3.1), we have

$$
\int_{0}^{d\left(A x_{n}, B \zeta\right)} \varphi(t) d t \leq \int_{0}^{\Theta\left(x_{n}, \zeta\right)} \varphi(t) d t-\mathcal{W}\left(\int_{0}^{\Theta\left(x_{n}, \zeta\right)} \varphi(t) d t\right)
$$

where

$$
\begin{gathered}
\Theta\left(x_{n}, \zeta\right)=\max \\
\left\{\begin{array}{c}
d\left(A x_{n}, S x_{n}\right), d(B \zeta, T \zeta), d\left(T \zeta, S x_{n}\right), \frac{1}{2}\left[d\left(A x_{n}, T \zeta\right)+d\left(B \zeta, S x_{n}\right)\right], \\
\frac{d\left(A x_{n}, S x_{n}\right) d(B \zeta, T \zeta)}{1+d\left(T \zeta, S x_{n}\right)}, \frac{d\left(A x_{n}, T \zeta\right) d\left(B \zeta, S x_{n}\right)}{1+d\left(T \zeta, S x_{n}\right)}, \frac{d\left(A x_{n}, T \zeta\right) d\left(B \zeta, S x_{n}\right)}{1+d\left(A x_{n}, B \zeta\right)} .
\end{array}\right\} .
\end{gathered}
$$

Passing to the limit as $n \rightarrow \infty$ in inequality (3.4), we have

$$
\int_{0}^{d(\zeta, B \zeta)} \varphi(t) d t \leq \int_{0}^{\Theta(\zeta, \zeta)} \varphi(t) d t-\mathcal{W}\left(\int_{0}^{\Theta(\zeta, \zeta)} \varphi(t) d t\right)
$$

where

$$
\Theta(\zeta, \zeta)=\max \left\{d(B \zeta, \zeta), d(\zeta, B \zeta), \frac{d^{2}(\zeta, T \zeta)}{1+d(B \zeta, \zeta)}, \frac{d^{2}(\zeta, T \zeta)}{1+d(\zeta, B \zeta)}\right\}=d(\zeta, B \zeta)
$$


Therefore we get

$$
\int_{0}^{d(\zeta, B \zeta)} \varphi(t) d t \leq \int_{0}^{d(\zeta, B \zeta)} \varphi(t) d t-\mathcal{W}\left(\int_{0}^{d(\zeta, B \zeta)} \varphi(t) d t\right)<\int_{0}^{d(\zeta, B \zeta)} \varphi(t) d t,
$$

which is a contradiction. Thus, we get $B \zeta=S \zeta=\zeta$. Therefore in all, $\zeta=A \zeta=$ $S \zeta=B \zeta=T \zeta$, i.e., $\zeta$ is a common fixed point of $A, B, S$ and $T$.

Finally, to prove the uniqueness of common fixed point, let $\zeta^{\prime}$ be another common fixed point of $A, B, S$ and $T$.

Putting $x=\zeta$ and $y=\zeta^{\prime}$ in inequality (3.1), we have

$$
\int_{0}^{d\left(\zeta, \zeta^{\prime}\right)} \varphi(t) d t=\int_{0}^{d\left(A \zeta, B \zeta^{\prime}\right)} \varphi(t) d t \leq \int_{0}^{\Theta\left(\zeta, \zeta^{\prime}\right)} \varphi(t) d t-\mathcal{W}\left(\int_{0}^{\left.\Theta\left(\zeta, \zeta^{\prime}\right)\right)} \varphi(t) d t\right),
$$

where

$$
\begin{gathered}
\Theta\left(\zeta, \zeta^{\prime}\right) \\
=\max \left\{\begin{array}{c}
d(A \zeta, S \zeta), d\left(B \zeta^{\prime}, T \zeta^{\prime}\right), d\left(T \zeta^{\prime}, S \zeta\right), \frac{1}{2}\left[d\left(A \zeta, T \zeta^{\prime}\right)+d\left(B \zeta^{\prime}, S \zeta\right)\right], \\
\frac{d(A \zeta, S \zeta) d\left(B \zeta^{\prime}, T \zeta^{\prime}\right)}{1+d\left(T \zeta^{\prime}, S \zeta\right)}, \frac{d\left(A \zeta, T \zeta^{\prime}\right) d\left(B \zeta^{\prime}, S \zeta\right)}{1+d\left(T \zeta^{\prime}, S \zeta\right)}, \frac{d\left(A \zeta, T \zeta^{\prime}\right) d\left(B \zeta^{\prime}, S \zeta\right)}{1+d\left(A \zeta, B \zeta^{\prime}\right)} \\
=\max \left\{d\left(\zeta^{\prime}, \zeta\right), d\left(\zeta, \zeta^{\prime}\right), \frac{d^{2}\left(\zeta, \zeta^{\prime}\right)}{1+d\left(\zeta^{\prime}, \zeta\right)}, \frac{d^{2}\left(\zeta, \zeta^{\prime}\right)}{1+d\left(\zeta, \zeta^{\prime}\right)}\right\} \\
=d\left(\zeta^{\prime}, \zeta\right) .
\end{array}\right\}
\end{gathered}
$$

Therefore

$$
\int_{0}^{d\left(\zeta, \zeta^{\prime}\right)} \varphi(t) d t \leq \int_{0}^{d\left(\zeta, \zeta^{\prime}\right)} \varphi(t) d t-\mathcal{W}\left(\int_{0}^{\left.d\left(\zeta, \zeta^{\prime}\right)\right)} \varphi(t) d t\right)<\int_{0}^{d\left(\zeta, \zeta^{\prime}\right)} \varphi(t) d t
$$

which is a contradiction. Hence $\zeta=\zeta^{\prime}$.jn

Part II: Since the pair $(A, S)$ (as well as $(B, T))$ is subcompatible and reciprocally continuous, therefore there exists a sequence $\left\{x_{n}\right\}$ in $X$ such that

$$
\lim _{n \rightarrow \infty} A x_{n}=\lim _{n \rightarrow \infty} S x_{n}=\zeta
$$

for some $\zeta \in X$, and

$$
\lim _{n \rightarrow \infty} d\left(A S x_{n}, S A x_{n}\right)=d(A \zeta, S \zeta)=0,
$$

whereas in respect to the pair $(B, T)$, there exists a sequence $\left\{y_{n}\right\}$ in $X$ such that

$$
\lim _{n \rightarrow \infty} B y_{n}=\lim _{n \rightarrow \infty} T y_{n}=\xi,
$$

for some $\xi \in X$, and

$$
\lim _{n \rightarrow \infty} d\left(B T y_{n}, T B y_{n}\right)=d(B \xi, T \xi)=0 .
$$


Therefore, $A \zeta=S \zeta$ and $B \xi=T \xi$, i.e., $\zeta$ is a coincidence point of the pair $(A, S)$ whereas $\xi$ is a coincidence point of the pair $(B, T)$. The rest of the proof can be completed on the lines of Part I.

\subsection{Consequences}

Some integral versions of well known results in the literature can be obtained as particular cases of our Theorem 3. For example, we state the following corollaries.

Corollary 1. Let $A, B, S, T: X \rightarrow X$ be four self mappings of a metric space $(X, d)$. If the pairs $(A, S)$ and $(B, T)$ are compatible and subsequentially continuous (alternately subcompatible and reciprocally continuous), then

(1) the pair $(A, S)$ has a coincidence point,

(2) the pair $(B, T)$ has a coincidence point.

We assume that, for all $x, y \in X$,

$$
\begin{gathered}
\int_{0}^{d(A x, B y)} \varphi(t) d t \leq \int_{0}^{\max \left\{d(A x, S x), d(B y, T y), d(T y, S x), \frac{1}{2}[d(A x, T y)+d(B y, S x)]\right\}} \varphi(t) d t \\
-\mathcal{W}\left(\int_{0}^{\max \left\{d(A x, S x), d(B y, T y), d(T y, S x), \frac{1}{2}[d(A x, T y)+d(B y, S x)]\right\}} \varphi(t) d t\right),
\end{gathered}
$$

where $\mathcal{W} \in \Psi$ and $\varphi \in \Phi$. Then $A, B, S$ and $T$ have a unique common fixed point in $X$.

Corollary 2. Let $A, B, S, T: X \rightarrow X$ be four self mappings of a metric space $(X, d)$. If the pairs $(A, S)$ and $(B, T)$ are compatible and subsequentially continuous (alternately subcompatible and reciprocally continuous), then

(1) the pair $(A, S)$ has a coincidence point,

(2) the pair $(B, T)$ has a coincidence point.

We assume that, for all $x, y \in X$,

$$
\int_{0}^{d(A x, B y)} \varphi(t) d t \leq \int_{0}^{d(T y, S x)} \varphi(t) d t-\mathcal{W}\left(\int_{0}^{d(T y, S x)} \varphi(t) d t\right),
$$

where $\mathcal{W} \in \Psi$ and $\varphi \in \Phi$. Then $A, B, S$ and $T$ have a unique common fixed point in $X$.

If $\mathcal{W}(t)=(1-k) t$ for $k \in(0,1)$ in Theorem 3, we have following result:

Corollary 3. Let $A, B, S, T: X \rightarrow X$ be four self mappings of a metric space $(X, d)$. If the pairs $(A, S)$ and $(B, T)$ are compatible and subsequentially continuous (alternately subcompatible and reciprocally continuous), then

(1) the pair $(A, S)$ has a coincidence point,

(2) the pair $(B, T)$ has a coincidence point. 
For all $x, y \in X$, we define

$$
\begin{gathered}
\Theta(x, y) \\
=\max \left\{\begin{array}{c}
d(A x, S x), d(B y, T y), d(T y, S x), \frac{1}{2}[d(A x, T y)+d(B y, S x)], \\
\frac{d(A x, S x) d(B y, T y)}{1+d(T y, S x)}, \frac{d(A x, T y) d(B y, S x)}{1+d(T y, S x)}, \frac{d(A x, T y) d(B y, S x)}{1+d(A x, B y)}
\end{array}\right\} .
\end{gathered}
$$

We assume that, for all $x, y \in X$,

$$
\int_{0}^{d(A x, B y)} \varphi(t) d t \leq k \int_{0}^{\Theta(x, y)} \varphi(t) d t
$$

where $k \in(0,1)$ and $\varphi \in \Phi$. Then $A, B, S$ and $T$ have a unique common fixed point in $X$.

If we take $\varphi(t)=1$ for all $t$ in Theorem 3, we get the following consequences:

Corollary 4. Let $A, B, S, T: X \rightarrow X$ be four self mappings of a metric space $(X, d)$. If the pairs $(A, S)$ and $(B, T)$ are compatible and subsequentially continuous (alternately subcompatible and reciprocally continuous), then

(1) the pair $(A, S)$ has a coincidence point,

(2) the pair $(B, T)$ has a coincidence point.

For all $x, y \in X$, we define

$$
=\max \left\{\begin{array}{c}
\Theta(x, y) \\
d(A x, S x), d(B y, T y), d(T y, S x), \frac{1}{2}[d(A x, T y)+d(B y, S x)], \\
\frac{d(A x, S x) d(B y, T y)}{1+d(T y, S x)}, \frac{d(A x, T y) d(B y, S x)}{1+d(T y, S x)}, \frac{d(A x, T y) d(B y, S x)}{1+d(A x, B y)}
\end{array}\right\} .
$$

We assume that, for all $x, y \in X$,

$$
d(A x, B y) \leq \Theta(x, y)-\mathcal{W}(\Theta(x, y))
$$

where $\mathcal{W} \in \Psi$. Then $A, B, S$ and $T$ have a unique common fixed point in $X$.

Corollary 5. Let $A, B, S, T: X \rightarrow X$ be four self mappings of a metric space $(X, d)$. If the pairs $(A, S)$ and $(B, T)$ are compatible and subsequentially continuous (alternately subcompatible and reciprocally continuous), then

(1) the pair $(A, S)$ has a coincidence point,

(2) the pair $(B, T)$ has a coincidence point.

We assume that, for all $x, y \in X$,

$$
\begin{gathered}
d(A x, B y) \\
\leq \max \left\{d(A x, S x), d(B y, T y), d(T y, S x), \frac{1}{2}[d(A x, T y)+d(B y, S x)]\right\} \\
-\mathcal{W}\left(\max \left\{d(A x, S x), d(B y, T y), d(T y, S x), \frac{1}{2}[d(A x, T y)+d(B y, S x)]\right\}\right)
\end{gathered}
$$

where $W \in \Psi$. Then $A, B, S$ and $T$ have a unique common fixed point in $X$. 
Corollary 6. Let $A, B, S, T: X \rightarrow X$ be four self mappings of a metric space $(X, d)$. If the pairs $(A, S)$ and $(B, T)$ are compatible and subsequentially continuous (alternately subcompatible and reciprocally continuous), then

(1) the pair $(A, S)$ has a coincidence point,

(2) the pair $(B, T)$ has a coincidence point.

We assume that, for all $x, y \in X$,

$$
d(A x, B y) \leq d(T y, S x)-\mathcal{W}(d(T y, S x))
$$

where $W \in \Psi$. Then $A, B, S$ and $T$ have a unique common fixed point in $X$.

If $\mathcal{W}(t)=(1-k) t$ for $k \in(0,1)$ in Corollary 4 , we have the following result:

Corollary 7. Let $A, B, S, T: X \rightarrow X$ be four self mappings of a metric space $(X, d)$. If the pairs $(A, S)$ and $(B, T)$ are compatible and subsequentially continuous (alternately subcompatible and reciprocally continuous), then

(1) the pair $(A, S)$ has a coincidence point,

(2) the pair $(B, T)$ has a coincidence point.

We assume that, for all $x, y \in X$,

$$
\begin{aligned}
& d(A x, B y) \\
& \leq k \max \left\{\begin{array}{c}
d(A x, S x), d(B y, T y), d(T y, S x), \frac{1}{2}[d(A x, T y)+d(B y, S x)], \\
\frac{d(A x, S x) d(B y, T y)}{1+d(T y, S x)}, \frac{d(A x, T y) d(B y, S x)}{1+d(T y, S x)}, \frac{d(A x, T y) d(B y, S x)}{1+d(A x, B y)}
\end{array}\right\}
\end{aligned}
$$

where $k \in(0,1)$. Then $A, B, S$ and $T$ have a unique common fixed point in $X$.

\subsection{Illustrative examples}

Now we furnish examples demonstrating the validity of the hypotheses and degree of generality of our results over some recently established results.

In the examples, we show the importance of each condition or property of Theorem 3 required for getting coincidence (common fixed) point of the mappings.

Example 1. Let $X=[0, \infty)$ and $d$ be the usual metric on $X$. Set $A=B$ and $S=T$. Define self mappings $A$ and $S$ by

$$
A x=\left\{\begin{array}{ll}
x^{2}, & \text { if } x \in[0,1) ; \\
2 x-1, & \text { if } x \in[1, \infty) ;
\end{array} \quad S x= \begin{cases}3 x-2, & \text { if } x \in[0,1) \\
x+3, & \text { if } x \in[1, \infty) .\end{cases}\right.
$$

Consider the sequence $\left\{x_{n}\right\}=\left\{1-\frac{1}{n}\right\}_{n \in \mathbb{N}}$ in $X$. Then

$$
\lim _{n \rightarrow \infty} A x_{n}=\lim _{n \rightarrow \infty}\left(1-\frac{1}{n}\right)^{2}=1=\lim _{n \rightarrow \infty} S x_{n}=\lim _{n \rightarrow \infty} 3\left(1-\frac{1}{n}\right)-2
$$

Also,

$$
\lim _{n \rightarrow \infty} A S x_{n}=\lim _{n \rightarrow \infty} A\left(1-\frac{3}{n}\right)=\lim _{n \rightarrow \infty}\left(1-\frac{3}{n}\right)^{2}=1=A(0),
$$




$$
\lim _{n \rightarrow \infty} S A x_{n}=\lim _{n \rightarrow \infty} S\left(1-\frac{1}{n}\right)^{2}=\lim _{n \rightarrow \infty} 3\left(1-\frac{1}{n}\right)^{2}-2=1 \neq S(1)
$$

but

$$
\lim _{n \rightarrow \infty} d\left(A S x_{n}, S A x_{n}\right)=0 .
$$

Thus, the pair $(A, S)$ is compatible but neither subsequentially continuous nor reciprocally continuous. By routine calculation we can check that the condition (3.1) is not satisfied. Therefore Theorem 3 cannot be used to prove the existence of coincidence point of $A$ and $S$. Note that this example cannot be covered by those fixed point theorems which involve compatibility and reciprocal continuity both or by involving conditions on completeness (or closedness) of underlying space (or subspaces). Also, in this example neither $X$ is complete nor any range-space is closed, since $A(X)=[0,1) \cup[1, \infty)$ and $S(X)=[-2,1) \cup[4, \infty)$.

Example 2. Let $X=[0, \infty)$ and $d$ be the usual metric on $X$. Set $A=B$ and $S=T$. Define the self mappings $A$ and $S$ by

$$
A x=\left\{\begin{array}{ll}
2, & \text { if } x \in[0,3) ; \\
x, & \text { if } x \in[3, \infty) ;
\end{array} \quad S x= \begin{cases}2 x-4, & \text { if } x \in[0,3] \\
3, & \text { if } x \in(3, \infty) .\end{cases}\right.
$$

Consider the sequence $\left\{x_{n}\right\}=\left\{3+\frac{1}{n}\right\}_{n \in \mathbb{N}}$ in $X$. Then

$$
\lim _{n \rightarrow \infty} A x_{n}=\lim _{n \rightarrow \infty}\left(3+\frac{1}{n}\right)=3=\lim _{n \rightarrow \infty} S x_{n}=\lim _{n \rightarrow \infty} 3 .
$$

Also,

$$
\lim _{n \rightarrow \infty} A S x_{n}=\lim _{n \rightarrow \infty} A 3=3=A(3), \lim _{n \rightarrow \infty} S A x_{n}=\lim _{n \rightarrow \infty} S\left(3+\frac{1}{n}\right)=3 \neq S(3),
$$

but

$$
\lim _{n \rightarrow \infty} d\left(A S x_{n}, S A x_{n}\right)=0 .
$$

Thus, the pair $(A, S)$ is compatible but not reciprocally continuous.

Consider another sequence $\left\{x_{n}\right\}=\left\{3-\frac{1}{n}\right\}_{n \in \mathbb{N}}$ in $X$. Then

$$
\lim _{n \rightarrow \infty} A x_{n}=\lim _{n \rightarrow \infty}\left(3-\frac{1}{n}\right)=2 \lim _{n \rightarrow \infty} S x_{n}=\lim _{n \rightarrow \infty} 2\left(3-\frac{1}{n}\right)-4=2 .
$$

Next,

and

$$
\begin{gathered}
\lim _{n \rightarrow \infty} A S x_{n}=\lim _{n \rightarrow \infty} A\left(3-\frac{1}{n}\right)=2=A(2), \\
\lim _{n \rightarrow \infty} S A x_{n}=\lim _{n \rightarrow \infty} S 2=0 \neq S(2),
\end{gathered}
$$

$$
\lim _{n \rightarrow \infty} d\left(A S x_{n}, S A x_{n}\right) \neq 0 .
$$

Thus, the pair $(A, S)$ is subsequentially continuous but not compatible. By routine calculation we can check that the condition (3.1) is not satisfied. Therefore Theorem 
3 do not imply the existence of coincidence point of $A$ and $S$. It is noted that this example cannot be covered by those fixed point theorems which involve compatibility and reciprocal continuity both or by involving conditions on completeness (or closedness) of underlying space (or subspaces). Also, in this example neither $X$ is complete nor any range-space are closed, since $A(X)=\{2\} \cup[3, \infty)$ and $S(X)=[-4,2] \cup\{3\}$.

Example 3. Let $X=[0, \infty)$ and $d$ be the usual metric on $X$. Set $A=B$ and $S=T$. Define self mappings $A$ and $S$ by

$$
A x=\left\{\begin{array}{ll}
\frac{x}{6}, & \text { if } x \in[0,2] ; \\
2 x-2, & \text { if } x \in(2, \infty) ;
\end{array} \quad S x= \begin{cases}\frac{x}{4}, & \text { if } x \in[0,2] \\
3 x-4, & \text { if } x \in(2, \infty) .\end{cases}\right.
$$

Consider the sequence $\left\{x_{n}\right\}=\left\{\frac{1}{n}\right\}_{n \in \mathbb{N}}$ in $X$. Then

$$
\lim _{n \rightarrow \infty} A x_{n}=\lim _{n \rightarrow \infty}\left(\frac{1}{6 n}\right)=0, \lim _{n \rightarrow \infty} S x_{n}=\lim _{n \rightarrow \infty}\left(\frac{1}{4 n}\right)=0 .
$$

Also,

$$
\begin{aligned}
& \lim _{n \rightarrow \infty} A S x_{n}=\lim _{n \rightarrow \infty} A\left(\frac{1}{4 n}\right)=\lim _{n \rightarrow \infty}\left(\frac{1}{24 n}\right)=0=A(0), \\
& \lim _{n \rightarrow \infty} S A x_{n}=\lim _{n \rightarrow \infty} S\left(\frac{1}{6 n}\right)=\lim _{n \rightarrow \infty}\left(\frac{1}{24 n}\right)=0=S(0),
\end{aligned}
$$

and

$$
\lim _{n \rightarrow \infty} d\left(A S x_{n}, S A x_{n}\right)=0 .
$$

Consider another sequence $\left\{x_{n}\right\}=\left\{2+\frac{1}{n}\right\}_{n \in \mathbb{N}}$ in $X$. Then

$$
\lim _{n \rightarrow \infty} A x_{n}=\lim _{n \rightarrow \infty} 2\left(2+\frac{1}{n}\right)-2=2=\lim _{n \rightarrow \infty}\left(4+\frac{4}{n}-2\right)=2=\lim _{n \rightarrow \infty} S x_{n} .
$$

Also,

$$
\begin{aligned}
& \lim _{n \rightarrow \infty} A S x_{n}=\lim _{n \rightarrow \infty} A\left(2+\frac{3}{n}\right)=\lim _{n \rightarrow \infty} 2\left(2+\frac{3}{n}-2\right)=2 \neq A(2), \\
& \lim _{n \rightarrow \infty} S A x_{n}=\lim _{n \rightarrow \infty} S\left(2+\frac{2}{n}\right)=\lim _{n \rightarrow \infty}\left(6+\frac{6}{n}-4\right)=2 \neq S(2),
\end{aligned}
$$

but $\lim _{n \rightarrow \infty} d\left(A S x_{n}, S A x_{n}\right)=0$. Thus, the pair $(A, S)$ is compatible as well as subsequentially continuous but not reciprocally continuous. By Theorem $3, A$ and $S$ have a coincidence point; here $u=0$ is a coincidence point of $A$ and $S$. It is noted by routine calculation that condition (3.1) is satisfied for $\mathcal{W}(t)=\frac{2 t}{3}$ and $\varphi(s)=1$. Thus, all the conditions of Theorem 3 (also of Corollary 4 ) are satisfied and 0 is a unique common fixed point of the pairs $(A, S)$ and $(B, T)$.

Now, we support the uniqueness of the common fixed point of the pairs $(A, S)$ and $(B, T)$ of Theorem 3 by the following example. Note that inequality (3.1) is necessary to prove the existence and uniqueness of the pairs $(A, S)$ and $(B, T)$. 
Example 4. Let $X=\{0,1,2,3, \ldots\}$ and consider the metric $d: X \times X \rightarrow X$ given by

$$
d(x, y)= \begin{cases}0, & \text { if } x=y \\ \max \{x, y\}, & \text { if } x \neq y\end{cases}
$$

Define $A, B, S, T: X \rightarrow X$ by

$$
A x=\left\{\begin{array}{ll}
0, & \text { if } x=0 ; \\
2 x+1, & \text { if } x \neq 0 ;
\end{array} \quad B x= \begin{cases}0, & \text { if } x=0 \\
2 x+2, & \text { if } x \neq 0\end{cases}\right.
$$

and

$$
S x=\left\{\begin{array}{ll}
0, & \text { if } x=0 ; \\
4 x+4, & \text { if } x \neq 0 ;
\end{array} \quad T x= \begin{cases}0, & \text { if } x=0 \\
4 x+2, & \text { if } x \neq 0\end{cases}\right.
$$

Also, define $\varphi, \mathcal{W}:[0,+\infty) \rightarrow[0,+\infty)$ by $\varphi(t)=2 t$ and $\mathcal{W}(t)=\sqrt{t}$. Then:

(1) The pairs $(A, S)$ and $(B, T)$ are compatible and subsequentially continuous.

(2) $\varphi$ is a Lebesgue-integrable function which is summable, nonnegative and such that $\int_{0}^{\epsilon} \varphi(t) d t>0$ for all $\epsilon>0$.

(3) $\mathcal{W} \in \Psi$.

(4) For any $x, y \in X$, we have

$$
\int_{0}^{d(A x, B y)} \varphi(t) d t \leq \int_{0}^{\Theta(x, y)} \varphi(t) d t-\mathcal{W}\left(\int_{0}^{\Theta(x, y)} \varphi(t) d t\right),
$$

where

$$
=\max \left\{\begin{array}{c}
\Theta(x, y) \\
d(A x, S x), d(B y, T y), d(T y, S x), \frac{1}{2}[d(A x, T y)+d(B y, S x)], \\
\frac{d(A x, S x) d(B y, T y)}{1+d(T y, S x)}, \frac{d(A x, T y) d(B y, S x)}{1+d(T y, S x)}, \frac{d(A x, T y) d(B y, S x)}{1+d(A x, B y)}
\end{array}\right\} .
$$

Proof. To prove (1), take $x_{n}=0$ for all but finitely many $n$. Then $A x_{n}=0$ and $S x_{n}=0$ for all but finitely many $n$. Hence, $d\left(A x_{n}, 0\right) \rightarrow 0$ and $d\left(S x_{n}, 0\right) \rightarrow 0$ as $n \rightarrow+\infty$; that is, $\lim _{n \rightarrow+\infty} A x_{n}=0$ and $\lim _{n \rightarrow+\infty} S x_{n}=0$. Also $\lim _{n \rightarrow+\infty} S A x_{n}=0=S 0$ and $\lim _{n \rightarrow+\infty} A S x_{n}=0=A 0$.

The pair $(A, S)$ is compatible and subsequentially continuous. Similarly, we can show that the pair $(B, T)$ is compatible and subsequentially continuous. The proof of (2) and (3) is clear. To prove (4), given $x, y \in X$, we divide the proof into the following cases:

Case 1: Let $x=y=0$. Here $A x=B y=S x=T y=0$. Thus condition (4) holds trivially. 
Case 2. Let $x=0$ and $y \neq 0$. Here $A x=0, B y=2 y+2, S x=0, T y=4 y+2$. Thus $d(A x, B y)=2 y+2$ and $d(S x, T y)=4 y+2$. Therefore

$$
\begin{aligned}
\int_{0}^{d(A x, B y)} \varphi(t) d t & =\int_{0}^{2 y+2}(2 t) d t=(2 y+2)^{2} \leq(4 y+2)^{2}-(4 y+2) \\
& =d^{2}(S x, T y)-d(S x, T y) \leq[\Theta(x, y)]^{2}-\Theta(x, y) \\
& =\int_{0}^{\Theta(x, y)} 2 t d t-\mathfrak{W}\left(\int_{0}^{\Theta(x, y)} 2 t d t\right) \\
& =\int_{0}^{\Theta(x, y)} \varphi(t) d t-\mathfrak{W}\left(\int_{0}^{\Theta(x, y)} \varphi(t) d t\right) .
\end{aligned}
$$

Case 3. Let $x \neq 0$ and $y=0$. Here $A x=2 x+1, B y=0, S x=4 x+4, T y=0$. Thus $d(A x, B y)=2 x+1$ and $d(S x, T y)=4 x+4$. Therefore

$$
\begin{aligned}
\int_{0}^{d(A x, B y)} \varphi(t) d t & =\int_{0}^{2 x+1}(2 t) d t=(2 x+1)^{2} \leq(4 x+4)^{2}-(4 x+4) \\
& =d^{2}(S x, T y)-d(S x, T y) \leq[\Theta(x, y)]^{2}-\Theta(x, y) \\
& =\int_{0}^{\Theta(x, y)} 2 t d t-\mathfrak{W}\left(\int_{0}^{\Theta(x, y)} 2 t d t\right) \\
& =\int_{0}^{\Theta(x, y)} \varphi(t) d t-\mathfrak{W}\left(\int_{0}^{\Theta(x, y)} \varphi(t) d t\right) .
\end{aligned}
$$

Case 4. Let $x>y>0$.

- If $x=2 y+1$, that is $y=\frac{x-1}{2}$, then $A x=2 x+1, B y=x+1, S x=4 x+4$, and $T y=2 x$. Thus $d(A x, B y)=2 x+1$ and $d(S x, T y)=4 x+4$. Therefore

$$
\begin{aligned}
\int_{0}^{d(A x, B y)} \varphi(t) d t & =\int_{0}^{2 x+1}(2 t) d t=(2 x+1)^{2} \leq(4 x+4)^{2}-(4 x+4) \\
& =d^{2}(S x, T y)-d(S x, T y) \leq[\Theta(x, y)]^{2}-\Theta(x, y) \\
& =\int_{0}^{\Theta(x, y)} 2 t d t-\mathcal{W}\left(\int_{0}^{\Theta(x, y)} 2 t d t\right) \\
& =\int_{0}^{\Theta(x, y)} \varphi(t) d t-\mathcal{W}\left(\int_{0}^{\Theta(x, y)} \varphi(t) d t\right) .
\end{aligned}
$$

- If $x>2 y+1$, then $A x=2 x+1, B y=x+1, S x=4 x+4$, and $T y=2 x$. Thus $d(A x, B y)=2 x+1$ and $d(S x, T y)=4 x+4$. Therefore as before we get the conclusion.

Case 5. Let $y>x>0$. If $y=2 x+2$, that is $x=\frac{y-2}{2}$, then $A x=y-1, B y=y+$ $1, S x=2 y$, and $T y=4 y+2$. Thus $d(A x, B y)=y+1$ and $d(S x, T y)=4 x+2$. 
Therefore

$$
\begin{aligned}
\int_{0}^{d(A x, B y)} \varphi(t) d t & =\int_{0}^{y+1}(2 t) d t=(y+1)^{2} \leq(4 x+2)^{2}-(4 x+2) \\
& =d^{2}(S x, T y)-d(S x, T y) \leq[\Theta(x, y)]^{2}-\Theta(x, y) \\
& =\int_{0}^{\Theta(x, y)} 2 t d t-\mathcal{W}\left(\int_{0}^{\Theta(x, y)} 2 t d t\right) \\
& =\int_{0}^{\Theta(x, y)} \varphi(t) d t-\mathcal{W}\left(\int_{0}^{\Theta(x, y)} \varphi(t) d t\right) .
\end{aligned}
$$

Thus in all cases contractive condition (3.1) is satisfied. Hence, all the hypotheses of Theorem 3 are satisfied and 0 is a unique common fixed point of the pairs $(A, S)$ and $(B, T)$. Note that all the involved mappings are discontinuous at their unique common fixed point.

\section{COMMON FIXED POINT RESUlTS UNDER GENERALIZED $\phi$-CONTRACTIVE CONDITIONS}

In this section we prove our results by taking into consideration different contractive condition, namely the one known as generalized $\phi$-contractive condition.

In what follows, we denote

$\Phi_{1}$

$=\left\{\begin{array}{c}\phi:\left(\mathbb{R}^{+}\right)^{9} \rightarrow \mathbb{R}^{+}: \phi \text { is upper semicontinuous and nondecreasing in } \\ \text { each coordinate variable and } \phi_{1}(t)=\max \{\phi(t, t, t, t, t, t, t, t, 0,), \\ \phi(0,0, t, 0, t, t, t, 0, t)\}<t\end{array}\right\}$

and

$\Phi_{2}=\left\{\begin{array}{c}\phi:\left(\mathbb{R}^{+}\right)^{7} \rightarrow \mathbb{R}^{+}: \phi \text { is upper semicontinuous and nondecreasing } \\ \text { in each coordinate variable and } \phi_{2}(t)=\phi(t, t, t, t, t, t, t)<t\end{array}\right\}$.

Theorem 4. Let $A, B, S, T: X \rightarrow X$ be four self mappings of a metric space $(X, d)$. If the pairs $(A, S)$ and $(B, T)$ are compatible and subsequentially continuous (alternately subcompatible and reciprocally continuous), then

(1) the pair $(A, S)$ has a coincidence point,

(2) the pair $(B, T)$ has a coincidence point.

If there exists $\phi \in \Phi_{1}$ such that

$$
\int_{0}^{d(A x, B y)} \varphi(t) d t
$$




$$
\leq \phi\left(\begin{array}{c}
\int_{0}^{d(A x, S x)} \varphi(t) d t, \int_{0}^{d(B y, T y)} \varphi(t) d t, \int_{0}^{d(S x, T y)} \varphi(t) d t, \\
\int_{0}^{\frac{1}{2}[d(A x, S x)+d(B y, T y)]} \varphi(t) d t, \int_{0}^{\frac{1}{2}[d(A x, S x)+d(S x, T y)]} \varphi(t) d t, \\
\int_{0}^{\frac{1}{2}[d(B y, T y)+d(S x, T y)]} \varphi(t) d t, \int_{0}^{\frac{1}{2}[d(A x, T y)+d(B y, S x)]} \varphi(t) d t, \\
\int_{0}^{\frac{d(A x, S x) d(B y, T y)}{1+d(A x, B y)}} \varphi(t) d t, \int_{0}^{\frac{d(A x, T y) d(B y, S x)}{1+d(A x, B y)}} \varphi(t) d t
\end{array}\right)
$$

for all $x, y \in X$ and some $\varphi \in \Phi$, then $A, B, S$ and $T$ have a unique common fixed point in $X$.

Proof. Suppose the pair $(A, S)$ (as well as $(B, T))$ is subsequentially continuous and compatible. Then there exists a sequence $\left\{x_{n}\right\}$ in $X$ such that

$$
\lim _{n \rightarrow \infty} A x_{n}=\lim _{n \rightarrow \infty} S x_{n}=u,
$$

for some $u \in X$, and

$$
\lim _{n \rightarrow \infty} d\left(A x_{n}, S y_{n}\right)=d(A u, S u)=0,
$$

with $A u=S u$, whereas in respect to the pair $(B, T)$, there exists a sequence $\left\{y_{n}\right\}$ in $X$ such that

for some $w \in X$, and

$$
\lim _{n \rightarrow \infty} B y_{n}=\lim _{n \rightarrow \infty} T y_{n}=w,
$$

$$
\lim _{n \rightarrow \infty} d\left(B y_{n}, T y_{n}\right)=d(B w, T w)=0,
$$

with $B w=T w$. Hence, $u$ is a coincidence point of the pair $(A, S)$, whereas $w$ is a coincidence point of the pair $(B, T)$.

Now we assert that $u=w$. To accomplish this, using inequality (4.1) with $x=x_{n}$, $y=y_{n}$, we have

$$
\begin{gathered}
\int_{0}^{d\left(A x_{n}, B y_{n}\right)} \varphi(t) d t \\
\leq \phi\left(\begin{array}{c}
\int_{0}^{d\left(A x_{n}, S x_{n}\right)} \varphi(t) d t, \int_{0}^{d\left(B y_{n}, T y_{n}\right)} \varphi(t) d t, \int_{0}^{d\left(S x_{n}, T y_{n}\right)} \varphi(t) d t, \\
\int_{0}^{\frac{1}{2}\left[d\left(A x_{n}, S x_{n}\right)+d\left(B y_{n}, T y_{n}\right)\right]} \varphi(t) d t, \int_{0}^{\frac{1}{2}\left[d\left(A x_{n}, S x_{n}\right)+d\left(S x_{n}, T y_{n}\right)\right]} \varphi(t) d t, \\
\int_{0}^{\frac{1}{2}\left[d\left(B y_{n}, T y_{n}\right)+d\left(S x_{n}, T y_{n}\right)\right]} \varphi(t) d t, \int_{0}^{\frac{1}{2}\left[d\left(A x_{n}, T y_{n}\right)+d\left(B y_{n}, S x_{n}\right)\right]} \varphi(t) d t \\
\int_{0}^{\frac{d\left(A x_{n}, S x_{n}\right) d\left(B y_{n}, T y_{n}\right)}{1+d\left(A x_{n}, B y_{n}\right)}} \varphi(t) d t, \int_{0}^{\frac{d\left(A x_{n}, T y_{n}\right) d\left(B y_{n}, S x_{n}\right)}{1+d\left(A x_{n}, B y_{n}\right)}} \varphi(t) d t
\end{array}\right) .
\end{gathered}
$$

Passing to the limit as $n \rightarrow \infty$ in inequality (4.2), we get

$$
\begin{aligned}
\int_{0}^{d(u, w)} \varphi(t) d t & \leq \phi\left(\begin{array}{c}
0,0, \int_{0}^{d(u, w)} \varphi(t) d t, 0, \int_{0}^{\frac{1}{2} d(u, w)} \varphi(t) d t, \\
\int_{0}^{\frac{1}{2} d(u, w)} \varphi(t) d t, \int_{0}^{d(u, w)} \varphi(t) d t, 0, \int_{0}^{\frac{d^{2}(u, w)}{1+d(u, w)}} \varphi(t) d t
\end{array}\right) \\
& \leq \phi\left(\begin{array}{c}
0,0, \int_{0}^{d(u, w)} \varphi(t) d t, 0, \int_{0}^{d(u, w)} \varphi(t) d t \\
\int_{0}^{d(u, w)]} \varphi(t) d t, \int_{0}^{d(u, w)} \varphi(t) d t, 0, \int_{0}^{d(u, w)} \varphi(t) d t
\end{array}\right)
\end{aligned}
$$




$$
=\phi_{1}\left(\int_{0}^{d(u, w)} \varphi(t) d t\right)<\int_{0}^{d(u, w)} \varphi(t) d t
$$

a contradiction, so we have

$$
\int_{0}^{d(z, w)} \varphi(t) d t=0
$$

Hence, $u=w$. Now we prove that $A u=u$. Putting $x=u$ and $y=y_{n}$ in inequality (4.1), we obtain

$$
\begin{aligned}
& \int_{0}^{d\left(A u, B y_{n}\right)} \varphi(t) d t \\
& \leq \phi\left(\begin{array}{c}
\int_{0}^{d(A u, S u)} \varphi(t) d t, \int_{0}^{d\left(B y_{n}, T y_{n}\right)} \varphi(t) d t, \int_{0}^{d\left(S u, T y_{n}\right)} \varphi(t) d t, \\
\int_{0}^{\frac{1}{2}\left[d(A u, S u)+d\left(B y_{n}, T y_{n}\right)\right]} \varphi(t) d t, \int_{0}^{\frac{1}{2}\left[d(A u, S u)+d\left(S u, T y_{n}\right)\right]} \varphi(t) d t, \\
\int_{0}^{\frac{1}{2}\left[d\left(B y_{n}, T y_{n}\right)+d\left(S u, T y_{n}\right)\right]} \varphi(t) d t, \int_{0}^{\frac{1}{2}\left[d\left(A u, T y_{n}\right)+d\left(B y_{n}, S u\right)\right]} \varphi(t) d t, \\
\int_{0}^{\frac{d(A u, S u)\left(B y_{n}, T y_{n}\right)}{1+d\left(A u, B y_{n}\right)}} \varphi(t) d t, \int_{0}^{\frac{d\left(A u, T y_{n}\right) d\left(B y_{n}, S u\right)}{1+d\left(A u, B y_{n}\right)}} \varphi(t) d t
\end{array}\right) .
\end{aligned}
$$

Passing to the limit as $n \rightarrow \infty$ in inequality (4.3), we get

$$
\begin{gathered}
\int_{0}^{d(A u, u)} \varphi(t) d t \\
\leq \phi\left(\begin{array}{c}
0,0, \int_{0}^{d(A u, z)} \varphi(t) d t, 0, \int_{0}^{\frac{1}{2} d(A u, u)} \varphi(t) d t, \int_{0}^{\frac{1}{2} d(A u, u)} \varphi(t) d t, \\
\int_{0}^{d(A u, u)} \varphi(t) d t, 0, \int_{0}^{\frac{d^{2}(A u, d) u}{1+d(A u, u)}} \varphi(t) d t
\end{array}\right) \\
\leq \phi\left(\begin{array}{c}
0,0, \int_{0}^{d(A u, u)} \varphi(t) d t, 0, \int_{0}^{d(A u, u)} \varphi(t) d t, \int_{0}^{d(A u, u)} \varphi(t) d t \\
\int_{0}^{d(A u, u)} \varphi(t) d t, 0, \int_{0}^{d(A u, u)} \varphi(t) d t
\end{array}\right) \\
=\phi_{1}\left(\int_{0}^{d(A u, u)} \varphi(t) d t\right)<\int_{0}^{d(A u, u)} \varphi(t) d t
\end{gathered}
$$

a contradiction, so we have

$$
\int_{0}^{d(A u, u)} \varphi(t) d t=0
$$

and so $A u=u$. Therefore, $A u=S u=u$. Now we assert that $B u=u$. To accomplish this, on using inequality (4.1) with $x=x_{n}, y=u$, we have

$$
\int_{0}^{d\left(A x_{n}, B u\right)} \varphi(t) d t
$$




$$
\leq \phi\left(\begin{array}{c}
\int_{0}^{d\left(A x_{n}, S x_{n}\right)} \varphi(t) d t, \int_{0}^{d(B u, T u)} \varphi(t) d t, \int_{0}^{d\left(S x_{n}, T u\right)} \varphi(t) d t, \\
\int_{0}^{\frac{1}{2}\left[d\left(A x_{n}, S x_{n}\right)+d(B u, T u)\right]} \varphi(t) d t, \int_{0}^{\frac{1}{2}\left[d\left(A x_{n}, S x_{n}\right)+d\left(S x_{n}, T u\right)\right]} \varphi(t) d t, \\
\int_{0}^{\frac{1}{2}\left[d(B u, T u)+d\left(S x_{n}, T u\right)\right]} \varphi(t) d t, \int_{0}^{\frac{1}{2}\left[d\left(A x_{n}, T u\right)+d\left(B u, S x_{n}\right)\right]} \varphi(t) d t, \\
\int_{0}^{\frac{d\left(A x_{n}, S x_{n}\right) d(B u, T u)}{1+d\left(A x_{n}, B u\right)}} \varphi(t) d t, \int_{0}^{\frac{d\left(A x_{n}, T u\right) d\left(B u, S x_{n}\right)}{1+d\left(A x_{n}, B u\right)}} \varphi(t) d t
\end{array}\right) .
$$

Passing to the limit as $n \rightarrow \infty$ in inequality (4.4), we get

$$
\begin{gathered}
\int_{0}^{d(u, B u)} \varphi(t) d t \\
\leq \phi\left(\begin{array}{c}
0,0, \int_{0}^{d(u, B u)} \varphi(t) d t, 0, \int_{0}^{\frac{1}{2} d(u, B u)} \varphi(t) d t, \int_{0}^{\frac{1}{2} d(u, B u)} \varphi(t) d t, \\
\int_{0}^{d(B u, u)} \varphi(t) d t, 0, \int_{0}^{\frac{d^{2}(B u, u)}{1+d(B u, u)}} \varphi(t) d t
\end{array}\right) \\
\leq \phi\left(\begin{array}{c}
0,0, \int_{0}^{d(u, B u)} \varphi(t) d t, 0, \int_{0}^{d(u, B u)} \varphi(t) d t, \int_{0}^{d(u, B u)} \varphi(t) d t \\
\int_{0}^{d(B u, u)} \varphi(t) d t, 0, \int_{0}^{d(B u, u)} \varphi(t) d t
\end{array}\right) \\
\leq \phi_{1}\left(\int_{0}^{d(B u, u)} \varphi(t) d t\right)<\int_{0}^{d(B u, u)} \varphi(t) d t
\end{gathered}
$$

which is a contradiction, so we have

$$
\int_{0}^{d(z, B z)} \varphi(t) d t=0 .
$$

Thus $B z=S z=z$. Therefore in all, $z=A z=S z=B z=T z$, i.e., $z$ is a common fixed point of $A, B, S$ and $T$. The uniqueness of common fixed point is an easy consequence of inequality (4.1).

The proof is similar if we assume that $(A, S)$ (as well as $(B, T)$ ) is subcompatible and reciprocally continuous. This completes the proof of the theorem.

Now we state the following theorem whose proof is similar to the one of Theorem 4.

Theorem 5. Let $A, B, S, T: X \rightarrow X$ be four self mappings of a metric space $(X, d)$. If the pairs $(A, S)$ and $(B, T)$ are compatible and subsequentially continuous (alternately subcompatible and reciprocally continuous), then

(1) the pair $(A, S)$ has a coincidence point,

(2) the pair $(B, T)$ has a coincidence point.

If there exists $\phi \in \Phi_{2}$ such that

$$
\int_{0}^{d(A x, B y)} \varphi(t) d t
$$




$$
\leq \phi\left(\begin{array}{c}
\int_{0}^{d(A x, S x)} \varphi(t) d t, \int_{0}^{d(B y, T y)} \varphi(t) d t, \int_{0}^{d(S x, T y)} \varphi(t) d t, \\
\int_{0}^{\frac{1}{2}[d(A x, S x)+d(B y, T y)]} \varphi(t) d t, \int_{0}^{\frac{1}{2}[d(A x, S x)+d(S x, T y)]} \varphi(t) d t, \\
\int_{0}^{\frac{1}{2}[d(B y, T y)+d(S x, T y)]} \varphi(t) d t, \int_{0}^{\frac{1}{2}[d(A x, T y)+d(B y, S x)]} \varphi(t) d t
\end{array}\right)
$$

for all $x, y \in X$ and some $\varphi \in \Phi$, then $A, B, S$ and $T$ have a unique common fixed point in $X$.

\subsection{Consequences}

In this section we derive some consequences of Theorem 4 and Theorem 5.

If $\varphi(t)=1$ for all $t$ in Theorem 4 then we get the following natural result.

Corollary 8. Let $A, B, S, T: X \rightarrow X$ be four self mappings of a metric space $(X, d)$. If the pairs $(A, S)$ and $(B, T)$ are compatible and subsequentially continuous (alternately subcompatible and reciprocally continuous), then

(1) the pair $(A, S)$ has a coincidence point,

(2) the pair $(B, T)$ has a coincidence point.

If there exists $\phi \in \Phi_{1}$ such that

$$
\leq \phi\left(\begin{array}{c}
d(A x, B y) \\
d(A x, S x), d(B y, T y), d(S x, T y), \frac{1}{2}[d(A x, S x)+d(B y, T y)], \\
\frac{1}{2}[d(A x, S x)+d(S x, T y)], \frac{1}{2}[d(B y, T y)+d(S x, T y)], \\
\frac{1}{2}[d(A x, T y)+d(B y, S x)], \frac{d(A x, S x) d(B y, T y)}{1+d(A x, B y)}, \frac{d(A x, T y) d(B y, S x)}{1+d(A x, B y)}
\end{array}\right)
$$

for all $x, y \in X$, then $A, B, S$ and $T$ have a unique common fixed point in $X$.

If we consider $\varphi(t)=1$ for all $t$ in Theorem 5, we obtain the following corollary:

Corollary 9. Let $A, B, S, T: X \rightarrow X$ be four self mappings of a metric space $(X, d)$. If the pairs $(A, S)$ and $(B, T)$ are compatible and subsequentially continuous (alternately subcompatible and reciprocally continuous), then

(1) the pair $(A, S)$ has a coincidence point,

(2) the pair $(B, T)$ has a coincidence point.

If there exists $\phi \in \Phi_{2}$ such that

$$
\leq \phi\left(\begin{array}{c}
d(A x, B y) \\
d(A x, S x), d(B y, T y), d(S x, T y), \frac{1}{2}[d(A x, S x)+d(B y, T y)], \\
\frac{1}{2}[d(A x, S x)+d(S x, T y)], \frac{1}{2}[d(B y, T y)+d(S x, T y)], \\
\frac{1}{2}[d(A x, T y)+d(B y, S x)]
\end{array}\right)
$$

for all $x, y \in X$, then $A, B, S$ and $T$ have a unique common fixed point in $X$.

Remark 1. Theorems 3-5 extend the results of Altun and Türkoğlu [7,8], Aliouche [6], Rhoades [48], Li et al. [36] for single-valued mappings, whereas the conditions 
on completeness of the underlying subspaces and containment of ranges amongst involved mappings are relaxed.

On choosing $A, B, S$ and $T$ suitably in Theorems 3-5 and Corollaries 4-9, we can deduce several corollaries for three and two self mappings.

\subsection{Illustrative examples}

In what follows, we support the result of Theorem 5 by an example, inspired by [56].

Example 5. Let $X=\{0,1,2,3, \ldots\}$ and consider the metric $d: X \times X \rightarrow X$ given by

$$
d(x, y)= \begin{cases}0, & \text { if } x=y \\ x+y, & \text { if } x \neq y .\end{cases}
$$

Define $A, B, S, T: X \rightarrow X$ by

$$
A x=\left\{\begin{array}{ll}
0, & \text { if } x=0 ; \\
x+1, & \text { if } x \neq 0 ;
\end{array} \quad B x= \begin{cases}0, & \text { if } x=0 \\
x+2, & \text { if } x \neq 0\end{cases}\right.
$$

and

$$
S x=\left\{\begin{array}{ll}
0, & \text { if } x=0 ; \\
2 x+2, & \text { if } x \neq 0 ;
\end{array} \quad T x= \begin{cases}0, & \text { if } x=0 \\
2 x+1, & \text { if } x \neq 0\end{cases}\right.
$$

Also, define $\varphi:[0,+\infty) \rightarrow[0,+\infty)$ by $\varphi(t)=t e^{t}+t$. Then:

(1) The pairs $(A, S)$ and $(B, T)$ are compatible and subsequentially continuous.

(2) $\varphi$ is a Lebesgue-integrable function which is summable, nonnegative and such that $\int_{0}^{\epsilon} \varphi(t) d t>0$ for all $\epsilon>0$.

(3) For any $x, y \in X$, we have

$$
\int_{0}^{d(A x, B y)} \varphi(t) d t \leq e^{-1} \int_{0}^{\Delta(x, y)} \varphi(t) d t
$$

where

$$
=\max \left\{\begin{array}{c}
\Delta(x, y) \\
d(A x, S x), d(B y, T y), d(S x, T y), \frac{1}{2}[d(A x, S x)+d(B y, T y)], \\
\frac{1}{2}[d(A x, S x)+d(S x, T y)], \frac{1}{2}[d(B y, T y)+d(S x, T y)], \\
\frac{1}{2}[d(A x, T y)+d(B y, S x)]
\end{array}\right\} .
$$

Proof. We can prove (1) as in Example 4. The proof of (2) is clear. To prove (3), given $x, y \in X$, with $x \geq y$ and divide the proof into the following cases:

Case 1: $x=y=0$. Here $A x=B y=S x=T y=0$. Thus

$$
\int_{0}^{d(A x, A y)} \varphi(t) d t \leq e^{-1} \int_{0}^{\Delta(x, y)} \varphi(t) d t
$$


Case 2. $y=0$ and $x>0$. Then we have $A x=x+1, B y=0, S x=2 x+2$ and $T y=0$. Consequently, we obtain

$$
d(A x, B y)=d(x+1,0)=x+1
$$

and

$$
\begin{gathered}
\Delta(x, y) \\
=\max \left\{\begin{array}{c}
d(A x, S x), d(B y, T y), d(S x, T y), \frac{1}{2}[d(A x, S x)+d(B y, T y)], \\
\frac{1}{2}[d(A x, S x)+d(S x, T y)], \frac{1}{2}[d(B y, T y)+d(S x, T y)], \\
\frac{1}{2}[d(A x, T y)+d(B y, S x)] \\
=\max
\end{array}\right\} \\
\left\{\begin{array}{c}
d(x+1,2 x+2), d(B 0, T 0), d(2 x+2,0), \frac{1}{2}[d(x+1,2 x+2)+d(0,0)], \\
\frac{1}{2}[d(x+1,2 x+2)+d(2 x+2,0)], \frac{1}{2}[d(0,0)+d(x+1,0)], \\
\frac{1}{2}[d(x+1,0)+d(0,2 x+2)] \\
=3 x+3 .
\end{array}\right\}
\end{gathered}
$$

It follows that

$$
\begin{aligned}
\int_{0}^{d(A x, B y)} \varphi(t) d t & =\int_{0}^{x+1}\left(t e^{t}+t\right) d t=\int_{0}^{x+1}\left(t e^{t}\right) d t=(x+1) e^{x+1} \\
& \leq e^{-1}(3 x+3) e^{3 x+3}=e^{-1} \Delta(x, y) \times e^{\Delta(x, y)} \\
& =e^{-1} \int_{0}^{\Delta(x, y)} \varphi(t) d t
\end{aligned}
$$

Case 3. Suppose $x>y>0$. We need to consider the following subcases:

- If $x=y+1$, or equivalently $y=x-1$, then we have $d(A x, B y)=d(A x, B(x-$ 1)) $=d(x+1, x+1)=0$.

- If $x>y+1$, then we have $A x=x+1, B y=y+2, S x=2 x+2$ and $T y=2 y+$ 1. Now, if $x=2 y$, then $d(A x, B y)=d(A(2 y), B y)=d(2 y+1, y+2)=3 y+3$ and

$$
\begin{gathered}
\Delta(x, y) \\
=\max \left\{\begin{array}{c}
d(A x, S x), d(B y, T y), d(S x, T y), \frac{1}{2}[d(A x, S x)+d(B y, T y)], \\
\frac{1}{2}[d(A x, S x)+d(S x, T y)], \frac{1}{2}[d(B y, T y)+d(S x, T y)], \\
\frac{1}{2}[d(A x, T y)+d(B y, S x)]
\end{array}\right\} \\
=\max \left\{\begin{array}{c}
d(2 y+1,4 y+2), d(y+2,2 y+1), d(4 y+2,2 y+1), \\
\frac{1}{2}[d(2 y+1,4 y+2)+d(y+2+2 y+1)], \\
\frac{1}{2}[d(2 y+1,4 y+2)+d(4 y+2,2 y+1)], \\
\frac{1}{2}[d(y+2+2 y+1)+d(4 y+2,2 y+1)], \\
\frac{1}{2}[d(2 y+1,2 y+1)+d(y+2,4 y+2)] \\
=6 y+3 .
\end{array}\right\}
\end{gathered}
$$


Thus we get

$$
\begin{aligned}
\int_{0}^{d(A x, B y)} \varphi(t) d t & =\int_{0}^{3 y+3}\left(t e^{t}+t\right) d t=\int_{0}^{3 y+3}\left(t e^{t}\right) d t=(3 x+3) e^{3 y+3} \\
& \leq e^{-1}(6 y+3) e^{6 y+3}=e^{-1} \Delta(x, y) \times e^{\Delta(x, y)} \\
& =e^{-1} \int_{0}^{\Delta(x, y)} \varphi(t) d t .
\end{aligned}
$$

- On the other hand, if $x<2 y$ then $d(A x, B y)=d(x+1, y+2)=x+y+3$ and

$$
\begin{aligned}
& \Delta(x, y) \\
& =\max \left\{\begin{array}{c}
d(A x, S x), d(B y, T y), d(S x, T y), \frac{1}{2}[d(A x, S x)+d(B y, T y)], \\
\frac{1}{2}[d(A x, S x)+d(S x, T y)], \frac{1}{2}[d(B y, T y)+d(S x, T y)], \\
\frac{1}{2}[d(A x, T y)+d(B y, S x)]
\end{array}\right\} \\
& =\max \left\{\begin{array}{c}
d(x+1,2 x+2), d(y+2,2 y+1), d(2 x+2,2 y+1), \\
\frac{1}{2}[d(x+1,2 x+2)+d(y+2,2 y+1)], \\
\frac{1}{2}[d(x+1,2 x+2)+d(2 x+2,2 y+1)], \\
\frac{1}{2}[d(y+2,2 y+1)+d(2 x+2,2 y+1)], \\
\frac{1}{2}[d(x+1,2 y+1)+d(y+2,2 x+2)]
\end{array}\right\} \\
& =2 x+2 y+3 \text {. }
\end{aligned}
$$

Thus we get

$$
\begin{aligned}
\int_{0}^{d(A x, B y)} \varphi(t) d t & =\int_{0}^{x+y+3}\left(t e^{t}+t\right) d t=\int_{0}^{x+y+3}\left(t e^{t}\right) d t=(3 x+3) e^{x+y+3} \\
& \leq e^{-1}(2 x+2 y+3) e^{2 x+2 y+3}=e^{-1} \Delta(x, y) \times e^{\Delta(x, y)} \\
& =e^{-1} \int_{0}^{\Delta(x, y)} \varphi(t) d t .
\end{aligned}
$$

- Finally, if $x>2 y$, then $d(A x, B y)=d(x+1, y+2)=x+y+3$ and $\Delta(x, y)$

$$
\begin{aligned}
& =\max \left\{\begin{array}{c}
d(A x, S x), d(B y, T y), d(S x, T y), \frac{1}{2}[d(A x, S x)+d(B y, T y)], \\
\frac{1}{2}[d(A x, S x)+d(S x, T y)], \frac{1}{2}[d(B y, T y)+d(S x, T y)], \\
\frac{1}{2}[d(A x, T y)+d(B y, S x)]
\end{array}\right\} \\
& =\max \left\{\begin{array}{c}
d(x+1,2 x+2), d(y+2,2 y+1), d(2 x+2,2 y+1), \\
\frac{1}{2}[d(x+1,2 x+2)+d(y+2,2 y+1)], \\
\frac{1}{2}[d(x+1,2 x+2)+d(2 x+2,2 y+1)], \\
\frac{1}{2}[d(y+2,2 y+1)+d(2 x+2,2 y+1)], \\
\frac{1}{2}[d(x+1,2 y+1)+d(y+2,2 x+2)]
\end{array}\right\} \\
& =3 x+3 .
\end{aligned}
$$


Therefore, we have

$$
\begin{aligned}
\int_{0}^{d(A x, B y)} \varphi(t) d t & =\int_{0}^{x+y+3}\left(t e^{t}+t\right) d t=\int_{0}^{x+y+3}\left(t e^{t}\right) d t=(x+y+3) e^{x+y+3} \\
& \leq e^{-1}(3 x+3) e^{3 x+3}=e^{-1} \Delta(x, y) \times e^{\Delta(x, y)} \\
& =e^{-1} \int_{0}^{\Delta(x, y)\}} \varphi(t) d t .
\end{aligned}
$$

Case 4. Assume $x=y>0$. Consequently, we get $d(A x, B x)=d(x+1, x+2)=$ $2 x+3$ and

$$
\begin{aligned}
& \Delta(x, y) \\
& =\max \left\{\begin{array}{c}
d(A x, S x), d(B y, T y), d(S x, T y), \frac{1}{2}[d(A x, S x)+d(B y, T y)], \\
\frac{1}{2}[d(A x, S x)+d(S x, T y)], \frac{1}{2}[d(B y, T y)+d(S x, T y)], \\
\frac{1}{2}[d(A x, T y)+d(B y, S x)]
\end{array}\right\} \\
& =\max \left\{\begin{array}{c}
d(x+1,2 x+2), d(x+2,2 x+1), d(2 x+2,2 x+1), \\
\frac{1}{2}[d(x+1,2 x+2)+d(x+2,2 x+1)], \\
\frac{1}{2}[d(x+1,2 x+2)+d(2 x+2,2 x+1)] \\
\frac{1}{2}[d(x+2,2 x+1)+d(2 x+2,2 x+1)], \\
\left.\frac{1}{2}[d(x+1,2 x+1)+d(x+2,2 x+2)]\right\}
\end{array}\right\} \\
& =4 x+3 .
\end{aligned}
$$

Therefore, we have

$$
\begin{aligned}
\int_{0}^{d(A x, B y)} \varphi(t) d t & =\int_{0}^{2 x+3}\left(t e^{t}+t\right) d t=\int_{0}^{2 x+3}\left(t e^{t}\right) d t=(2 x+3) e^{2 x+3} \\
& \leq e^{-1}(4 x+3) e^{4 x+3}=e^{-1} \Delta(x, y) \times e^{\Delta(x, y)} \\
& =e^{-1} \int_{0}^{\Delta(x, y)\}} \varphi(t) d t .
\end{aligned}
$$

If we define a function $\phi_{2}:[0,+\infty) \rightarrow[0,+\infty)$ by $\phi_{2}(t)=e^{-1} t$, for all $t \geq 0$, then clearly $\phi_{2} \in \Phi$. Thus, in all possible cases, the contractive condition (4.5) is satisfied. Hence, all the hypotheses of Theorem 5 are satisfied in this example and 0 is a unique common fixed point of the pairs $(A, S)$ and $(B, T)$. Note that all the involved mappings are discontinuous at their unique common fixed point.

Remark 2. Example 5 can also be used to illustrate Theorem 4.

\section{AN APPLICATION TO SYSTEMS OF INTEGRAL EQUATIONS}

Consider the following system of integral equations:

$$
u(t)=\int_{0}^{T} K_{1}(t, s, u(s)) d s+g(t),
$$




$$
\begin{aligned}
& u(t)=\int_{0}^{T} K_{2}(t, s, u(s)) d s+g(t), \\
& u(t)=\int_{0}^{T} K_{3}(t, s, u(s)) d s+g(t),
\end{aligned}
$$

$t \in I=[0, T]$, where $T>0$. The purpose of this section is to give an existence theorem for a solution of the system (5.1) using Corollary 9.

Consider the set

$$
C(I):=\{u: I \rightarrow \mathbb{R} \mid u \text { is continuous on } I\},
$$

and define $d: C(I) \times C(I) \rightarrow \mathbb{R}$ by:

$$
d(u, v)=\max _{t \in I}|u(t)-v(t)|, \quad \forall u, v \in C(I) .
$$

Then $(C(I), d)$ is a complete metric space. Define, further, mappings $T_{i}: C(I) \rightarrow$ $C(I)$ by

$$
T_{i} x(t)=\int_{0}^{T} K_{i}(t, s, x(s)) d s+g(t), \quad t \in I, \quad i \in\{1,2,3\} .
$$

Consider the following conditions:

(i) $K_{1}, K_{2}, K_{3}: I \times I \times \mathbb{R} \rightarrow \mathbb{R}$ and $g: I \rightarrow \mathbb{R}$ are continuous,

(ii) there exists a continuous function $G: I \times I \rightarrow \mathbb{R}_{+}$such that

$$
\phi\left(\begin{array}{c}
\left|K_{1}(t, s, u(t))-K_{2}(t, s, v(t))\right| \leq G(t, s) \\
\phi\left(\begin{array}{c}
\left|T_{1} u(t)-T_{3} u(t)\right|,\left|T_{2} v(t)-T_{3} v(t)\right|,\left|T_{3} u(t)-T_{3} v(t)\right|, \\
\frac{1}{2}\left[\left|T_{1} u(t)-T_{3} u(t)\right|+\left|T_{2} v(t)-T_{3} v(t)\right|\right], \\
\frac{1}{2}\left[\left|T_{1} u(t)-T_{3} u(t)\right|+\left|T_{3} u(t)-T_{3} v(t)\right|\right], \\
\frac{1}{2}\left[\left|T_{2} v(t)-T_{3} v(t)\right|+\left|T_{3} u(t)-T_{3} v(t)\right|\right], \\
\frac{1}{2}\left[\left|T_{1} u(t)-T_{3} v(t)\right|+\left|T_{2} v(t)-T_{3} u(t)\right|\right]
\end{array}\right)
\end{array}\right.
$$

for all $u, v \in C(I)$, and all $s, t \in I$,

(iii) $\max _{t \in I} \int_{0}^{T} G(t, s) d s<1$.

(iv) there exists $\left\{h_{n}\right\} \in C(I)$ such that $\lim _{n \rightarrow \infty} A_{1} h_{n}=\lim _{n \rightarrow \infty} A_{2} h_{n}=h^{*} \in$ $C(I)$ and

$\lim _{n \rightarrow \infty} \sup _{x \in I}\left|A_{1} A_{2} h_{n}-A_{2} A_{1} h_{n}\right|=0$,

(v) there exists $\left\{k_{n}\right\} \in C(I)$ such that $\lim _{n \rightarrow \infty} T_{1} k_{n}=\lim _{n \rightarrow \infty} T_{2} k_{n}=k^{*} \in$ $C(I)$ and

$\lim _{n \rightarrow \infty} \sup _{x \in I}\left|T_{1} T_{2} h_{n}-T_{2} T_{1} k_{n}\right|=0$.

We will prove the following result.

Theorem 6. Suppose that the hypotheses (i)-(v) hold. Then the system 5.1 has a unique solution $x^{*} \in C(I)$. 
Proof. Since $K_{i}$ and $g$, for $i=1,2,3$ are continuous, then also the operators $T_{i}$ from equation (5.2) are continuous and so reciprocally continuous. By hypothesis (iv) and (v) the pairs $\left(T_{1}, T_{3}\right)$ and $\left(T_{2}, T_{3}\right)$ are subcompatible with respect to $T_{3}$. Now, for all $u, v \in C(I)$, by (ii) and (iii), we have:

$$
\begin{gathered}
\left|T_{1} u(t)-T_{2} v(t)\right| \\
\leq \int_{0}^{T}\left|K_{1}(t, s, u(s))-K_{2}(t, s, v(s))\right| d s \\
\leq \int_{0}^{T} G(t, s) d s \\
\times \phi\left(\begin{array}{c}
\left|T_{1} u(t)-T_{3} u(t)\right|,\left|T_{2} v(t)-T_{3} v(t)\right|,\left|T_{3} u(t)-T_{3} v(t)\right|, \\
\frac{1}{2}\left[\left|T_{1} u(t)-T_{3} u(t)\right|+\left|T_{2} v(t)-T_{3} v(t)\right|\right], \\
\frac{1}{2}\left[\left|T_{1} u(t)-T_{3} u(t)\right|+\left|T_{3} u(t)-T_{3} v(t)\right|\right], \\
\frac{1}{2}\left[\left|T_{2} v(t)-T_{3} v(t)\right|+\left|T_{3} u(t)-T_{3} v(t)\right|\right], \\
\frac{1}{2}\left[\left|T_{1} u(t)-T_{3} v(t)\right|+\left|T_{2} v(t)-T_{3} u(t)\right|\right]
\end{array}\right) .
\end{gathered}
$$

On routine calculations, we get

$$
\begin{aligned}
& d\left(T_{1} u, T_{2} v\right) \\
& \leq \phi\left(\begin{array}{c}
d\left(T_{1} u, T_{3} u\right), d\left(T_{2} v, T_{3} v\right), d\left(T_{3} u, T_{3} v\right), \frac{1}{2}\left[d\left(T_{1} u, T_{3} u\right)+d\left(T_{2} v, T_{3} v\right)\right], \\
\frac{1}{2}\left[d\left(T_{1} u, T_{3} u\right)+d\left(T_{3} u, T_{3} v\right)\right] \\
\frac{1}{2}\left[d\left(T_{2} v, T_{3} v\right)+d\left(T_{3} u, T_{3} v\right)\right], \frac{1}{2}\left[d\left(T_{1} u, T_{3} v\right)+d\left(T_{2} v, T_{3} u\right)\right]
\end{array}\right) .
\end{aligned}
$$

Then, putting $A=T_{1}, B=T_{2}$ and $S=T=T_{3}$, Corollary 9 is applicable in the case $X=C(I)$, and so $T_{1}, T_{2}$ and $T_{3}$ have a unique common fixed point. Then, there exists a unique $x^{*} \in C(I)$, a common fixed point of $T$ and $S$, that is $x^{*}$ is a unique solution to (5.1).

\section{APPLICATIONS TO EXISTENCE THEOREMS FOR FUNCTIONAL EQUATIONS ARISING IN DYNAMIC PROGRAMMING}

The existence, uniqueness, and iterative approximations of solutions for several classes of functional equations arising in dynamic programming were studied by a lot of researchers. Bellman [14] first studied the existence of solutions for some classes of functional equations arising in dynamic programming. Bellman and Lee [15] pointed out that the basic form of the functional equations in dynamic programming is as follows:

$$
q(x)=\sup _{y \in D}\{G(x, y, q(\tau(x, y)))\}, \quad x \in W,
$$

where $\tau: W \times D \rightarrow W, g: W \times D \rightarrow \mathbb{R}, G: W \times D \times \mathbb{R} \rightarrow \mathbb{R}$ are mappings while $W \subseteq U$ is a state space, $D \subseteq V$ is a decision space and $U$ as well as $V$ are Banach spaces. 
In 1984, Bhakta and Mitra [16] obtained some existence theorem for the following functional equation which arises in multistage decision process related to dynamic programming

$$
q(x)=\sup _{y \in D}\{g(x, y)+G(x, y, q(\tau(x, y)))\}, \quad x \in W,
$$

where $\tau: W \times D \rightarrow W, g: W \times D \rightarrow \mathbb{R}, G: W \times D \times \mathbb{R} \rightarrow \mathbb{R}$ are mappings while $W \subseteq U$ is a state space, $D \subseteq V$ is a decision space and $U$ as well as $V$ are Banach spaces.

Thereafter a lot of work has been done in this direction and existence and uniqueness results were obtained for solutions and common solutions of some functional equations and systems of functional equations in dynamic programming with the use of fixed point results. For details see $[13,32,38,39,45,46]$ and the references therein.

Let $U$ and $V$ be Banach spaces, $W \subseteq U$ be a state space and $D \subseteq V$ be a decision space. Now, by using the fixed point results obtained in the previous section, we study the solvability of the following system of functional equations arising in dynamic programming:

$$
\left\{\begin{array}{l}
F_{i}(x)=\sup _{y \in D}\left\{g(x, y)+H_{i}\left(x, y, F_{i}(\tau(x, y))\right)\right\}, x \in W, i=1,2, \\
G_{i}(x)=\sup _{y \in D}\left\{g(x, y)+K_{i}\left(x, y, G_{i}(\tau(x, y))\right)\right\}, x \in W, i=1,2,
\end{array}\right.
$$

where $\tau: W \times D \rightarrow W, g: W \times D \rightarrow \mathbb{R}, H_{i}, K_{i}: W \times D \times \mathbb{R} \rightarrow \mathbb{R}$.

Let $C(W)$ denote the space of all continuous real-valued functions on $W$. Clearly, this space endowed with the metric given by

$$
d(h, k)=\sup _{x \in W}|h(x)-k(x)|, \text { for all } h, k \in C(W)
$$

is a complete metric space.

We will prove the following result.

Theorem 7. Let $H_{i}, K_{i}: W \times D \times \mathbb{R} \rightarrow \mathbb{R}$, for $i=1,2$, be four bounded functions and let $A_{i}, T_{i}: C(W) \rightarrow C(W)$, for $i=1,2$, be four operators defined by

$$
\begin{gathered}
A_{i} h(x)=\sup _{y \in D}\left\{g(x, y)+H_{i}(x, y, h(\tau(x, y)))\right\}, i=1,2, \\
T_{i} k(x)=\sup _{y \in D}\left\{g(x, y)+K_{i}(x, y, k(\tau(x, y)))\right\}, i=1,2,
\end{gathered}
$$

for all $h, k \in C(W)$ and $x \in W$. Assume that the following conditions hold:

(i) there exists $\left\{h_{n}\right\} \in C(W)$ such that $\lim _{n \rightarrow \infty} A_{1} h_{n}=\lim _{n \rightarrow \infty} A_{2} h_{n}=h^{*} \in$ $C(W)$ and $\lim _{n \rightarrow \infty} \sup _{x \in W}\left|A_{1} A_{2} h_{n}-A_{2} A_{1} h_{n}\right|=0$,

(ii) there exists $\left\{k_{n}\right\} \in C(W)$ such that $\lim _{n \rightarrow \infty} T_{1} k_{n}=\lim _{n \rightarrow \infty} T_{2} k_{n}=k^{*} \in$ $C(W)$ and $\lim _{n \rightarrow \infty} \sup _{x \in W}\left|T_{1} T_{2} h_{n}-T_{2} T_{1} k_{n}\right|=0$, 
(iii)

$$
\begin{aligned}
& \int_{0}^{\left|H_{1}(x, y, h(\tau(x, y)))-K_{1}(x, y, k(\tau(x, y)))\right|} \varphi(s) d s \\
& \leq \int_{0}^{\Theta(h, k)} \varphi(t) d t-W\left(\int_{0}^{\Theta(h, k)} \varphi(t) d t\right),
\end{aligned}
$$

where

$$
\begin{gathered}
\Theta(h, k)=\max \\
\left\{\begin{array}{c}
\left|A_{1} h-A_{2} h\right|,\left|T_{1} k-T_{2} k\right|,\left|T_{2} k-A_{2} k\right|, \frac{1}{2}\left[\left|A_{1} h-T_{2} k\right|+\left|T_{1} k-A_{2} k\right|\right], \\
\frac{\left|A_{1} k-A_{2} k\right|\left|T_{1} k-T_{2} k\right|}{1+\left|T_{2} k-A_{2} h\right|}, \frac{\left|A_{1} h-T_{2} k\right|\left|T_{1} k-A_{2} h\right|}{1+\left|T_{2} k-A_{2} h\right|}, \frac{\left|A_{1} h-T_{2} k\right|\left|T_{1} k-A_{2} h\right|}{1+\left|A_{1} h-T_{1} k\right|}
\end{array}\right\}
\end{gathered}
$$

where $h, k \in C(W), x \in W, y \in D, W \in \Psi$ and $\varphi: \mathbb{R}_{+} \rightarrow \mathbb{R}_{+}$is a non-negative summable Lebesgue integrable function such that

$$
\int_{0}^{\epsilon} \varphi(s) d s>0
$$

for each $\epsilon>0$. Then the system of functional equations (6.1) has a unique bounded solution.

Proof. Notice that the system of functional equations (6.1) has a unique bounded solution if and only if the operators (6.2) and (6.3) have a unique common fixed point. Now, since $H_{1}, H_{2}, K_{1}$ and $K_{2}$ are bounded, there exists a positive number $\Lambda$ such that

$$
\sup \left\{\left|H_{i}(x, y, z)\right|,\left|K_{i}(x, y, z)\right|:(x, y, z) \in W \times D \times \mathbb{R}, i=1,2\right\} \leq \Lambda .
$$

By using a property from the integration theory [30, Theorem 12.34], and the properties of $\varphi$, we conclude that for each positive number $\varepsilon$, there exists a positive number $\delta(\varepsilon)$ such that

$$
\int_{\Gamma} \varphi(s) d s \leq \varepsilon
$$

for all $\Gamma \subseteq[0,2 \Lambda]$ with $m(\Gamma) \leq \delta(\varepsilon)$, where $m(\Gamma)$ is the Lebesgue measure of $\Gamma$.

Let $x \in W$ and $h_{1}, h_{2} \in C(W)$, then there exist $y_{1}, y_{2} \in D$ such that

$$
\begin{aligned}
& A_{1} h_{1}(x)<g\left(x, y_{1}\right)+H_{1}\left(x, y_{1}, h_{1}\left(\tau\left(x, y_{1}\right)\right)\right)+\delta(\varepsilon), \\
& T_{1} h_{2}(x)<g\left(x, y_{2}\right)+K_{1}\left(x, y_{2}, h_{2}\left(\tau\left(x, y_{2}\right)\right)\right)+\delta(\varepsilon), \\
& A_{1} h_{1}(x) \geq g\left(x, y_{2}\right)+H_{1}\left(x, y_{2}, h_{1}\left(\tau\left(x, y_{2}\right)\right)\right), \\
& T_{1} h_{2}(x) \geq g\left(x, y_{1}\right)+K_{1}\left(x, y_{1}, h_{2}\left(\tau\left(x, y_{1}\right)\right)\right) .
\end{aligned}
$$

Then from (6.6) and (6.9), it follows easily that

$$
A_{1} h_{1}(x)-T_{1} h_{2}(x)<H_{1}\left(x, y_{1}, h_{1}\left(\tau\left(x, y_{1}\right)\right)\right)-K_{1}\left(x, y_{1}, h_{2}\left(\tau\left(x, y_{1}\right)\right)\right)+\delta(\varepsilon)
$$




$$
\leq\left|H_{1}\left(x, y_{1}, h_{1}\left(\tau\left(x, y_{1}\right)\right)\right)-K_{1}\left(x, y_{1}, h_{2}\left(\tau\left(x, y_{1}\right)\right)\right)\right|+\delta(\varepsilon) .
$$

Hence we get

$$
\begin{aligned}
& A_{1} h_{1}(x)-T_{1} h_{2}(x) \\
& <\left|H_{1}\left(x, y_{1}, h_{1}\left(\tau\left(x, y_{1}\right)\right)\right)-K_{1}\left(x, y_{1}, h_{2}\left(\tau\left(x, y_{1}\right)\right)\right)\right|+\delta(\varepsilon) .
\end{aligned}
$$

Similarly, from (6.7) and (6.8) we obtain

$$
\begin{aligned}
& T_{1} h_{2}(x)-A_{1} h_{1}(x) \\
& <\left|K_{1}\left(x, y_{2}, h_{2}\left(\tau\left(x, y_{2}\right)\right)\right)-H_{1}\left(x, y_{2}, h_{1}\left(\tau\left(x, y_{2}\right)\right)\right)\right|+\delta(\varepsilon) .
\end{aligned}
$$

Therefore, from (6.10) and (6.11) we have

$$
\begin{aligned}
& \left|A_{1} h_{1}(x)-T_{1} h_{2}(x)\right| \\
& <\left|H_{1}\left(x, y_{1}, h_{1}\left(\tau\left(x, y_{1}\right)\right)\right)-K_{1}\left(x, y_{1}, h_{2}\left(\tau\left(x, y_{1}\right)\right)\right)\right|+\delta(\varepsilon) .
\end{aligned}
$$

In view of (7), (6.5) and (6.12), it follows easily that

$$
\int_{0}^{\left|A_{1} h_{1}(x)-T_{1} h_{2}(x)\right|} \varphi(s) d s \leq \int_{0}^{\Theta\left(h_{1}, h_{2}\right)} \varphi(t) d t-\mathcal{W}\left(\int_{0}^{\Theta\left(h_{1}, h_{2}\right)} \varphi(t) d t\right)+\varepsilon
$$

where

$$
=\max \left\{\begin{array}{c}
\Theta\left(h_{1}, h_{2}\right) \\
\frac{\left|A_{1} h_{1}-A_{2} h_{1}\right|,\left|T_{1} h_{2}-T_{2} h_{2}\right|,\left|T_{2} h_{2}-A_{2} h_{2}\right|,}{2}\left[\left|A_{1} h_{1}-T_{2} h_{2}\right|+\left|T_{1} h_{2}-A_{2} h_{2}\right|\right], \frac{\left|A_{1} h_{2}-A_{2} h_{2}\right|\left|T_{1} h_{2}-T_{2} h_{2}\right|}{1+T_{2} h_{2}-A_{2} h_{1} \mid}, \\
\frac{\left|A_{1} h_{1}-T_{2} h_{2}\right|\left|T_{1} h_{2}-A_{2} h_{1}\right|}{1+\left|T_{2} h_{2}-A_{2} h_{1}\right|}, \frac{\left|A_{1} h_{1}-T_{2} h_{2}\right|\left|T_{1} h_{2}-A_{2} h_{1}\right|}{1+\left|A_{1} h_{1}-T_{1} h_{2}\right|}
\end{array}\right\} .
$$

Since the above inequality is true for any $x \in W$ and $\varepsilon>0$ is taken arbitrary, then we deduce easily that

$$
\int_{0}^{d\left(A_{1} h_{1}, T_{1} h_{2}\right)} \varphi(s) d s \leq \int_{0}^{\Theta_{d}\left(h_{1}, h_{2}\right)} \varphi(t) d t-\mathcal{W}\left(\int_{0}^{\Theta_{d}\left(h_{1}, h_{2}\right)} \varphi(t) d t\right),
$$

where

$$
\begin{aligned}
& \Theta_{d}\left(h_{1}, h_{2}\right) \\
& =\max \left\{\begin{array}{c}
d\left(A_{1} h_{1}, A_{2} h_{1}\right), d\left(T_{1} h_{2}, T_{2} h_{2}\right), d\left(T_{2} h_{2}, A_{2} h_{2}\right), \\
\frac{1}{2}\left[d\left(A_{1} h_{1}, T_{2} h_{2}\right)+d\left(T_{1} h_{2}, A_{2} h_{2}\right)\right], \frac{d\left(A_{1} h_{2}, A_{2} h_{2}\right) d\left(T_{1} h_{2}, T_{2} h_{2}\right)}{1+d\left(T_{2} h_{2}, A_{2} h_{1}\right)}, \\
\frac{d\left(A_{1} h_{1}, T_{2} h_{2}\right) d\left(T_{1} h_{2}, A_{2} h_{1}\right)}{1+d\left(T_{2} h_{2}, A_{2} h_{1}\right)}, \frac{d\left(A_{1} h_{1}, T_{2} h_{2}\right) d\left(T_{1} h_{2}, A_{2} h_{1}\right)}{1+d\left(A_{1} h_{1}, T_{1} h_{2}\right)}
\end{array}\right\} .
\end{aligned}
$$

Next, since $H_{i}$ and $K_{i}$, for $i=1,2$, are continuous, the operators (6.2) and (6.3) are also continuous and so reciprocally continuous. Also, by conditions (i) and (ii), the pairs $\left(A_{1}, A_{2}\right)$ and $\left(T_{1}, T_{2}\right)$ are subcompatible. Thus all the hypotheses of Theorem 3 are satisfied. Consequently, the operators (6.2) and (6.3) have a unique common fixed point, that is, the system of functional equations (6.1) has a unique bounded solution. 


\section{ACKNOWLEDGEMENT}

The author would like to thank the editor and anonymous reviewers for their constructive comments, which contributed to improve the presentation of the paper.

\section{REFERENCES}

[1] M. Aamri and D. Moutawakil, "Some new common fixed point theorems under strict contractive conditions," J. Math. Anal. Appl., vol. 270, no. 1, pp. 181-188, 2002.

[2] M. Abbas and B. Rhoades, "Common fixed point theorems for hybrid pairs of occasionally weakly compatible mappings satisfying generalized contractive condition of integral type," Fixed Point Theory Appl., vol. Article ID 54101, pp. 1-9, 2007.

[3] M. A. Al-Thagafi and N. Shahzad, "Generalized $I$-nonexpansive selfmaps and invariant approximations," Acta Math. Sinica (Eng. Ser.), vol. 24, no. 5, pp. 867-876, 2008.

[4] J. Ali and M. Imdad, "An implicit function implies several contraction conditions," Sarajevo J. Math., vol. 4, no. 2, pp. 269-285, 2008.

[5] A. Aliouche, "A common fixed point theorem for weakly compatible mappings in symmetric spaces satisfying a contractive condition of integral type," J. Math. Anal. Appl., vol. 322, no. 2, pp. 796-802, 2006.

[6] A. Aliouche, "Common fixed point theorems of Gregus type for weakly compatible mappings satisfying generalized contractive conditions," J. Math. Anal. Appl., vol. 341, no. 21, pp. 707-719, 2008.

[7] I. Altun and D. Türkoğlu, "Some fixed point theorems for weakly compatible mappings satisfying an implicit relation," Taiwanese J. Math., vol. 13, no. 4, pp. 1291-1304, 2009.

[8] I. Altun and D. Türkoğlu, "Some fixed point theorems for weakly compatible multivalued mappings satisfying some general contractive conditions of integral type," Bull. Iran. Math. Soc., vol. 36, no. 1, pp. 55-67, 2010.

[9] I. Altun, D. Türkoğlu, and B. Rhoades, "Fixed points of weakly compatible maps satisfying a general contractive condition of integral type," Fixed Point Theory Appl., vol. Article ID 17301, pp. 1-9, 2007.

[10] H. Aydi, "A common fixed point of integral type contraction in generalized metric spaces," J. Adv. Math. Stud., vol. 5, no. 1, pp. 111-117, 2012.

[11] H. Aydi, "A fixed point theorem for a contractive condition of integral type involving altering distances," Int. J. Nonlinear Anal. Appl., in press.

[12] S. Banach, "Sur les opérations dans les ensembles abstraits et leur application aux équations intégrales," Fund. Math., vol. 3, pp. 133-181, 1922.

[13] R. Baskaran and P. Subrahmanyam, "A note on the solution of a class of functional equations," Appl. Anal., vol. 22, pp. 235-241, 1986.

[14] R. Bellman, Methods of Nonliner Analysis, 2nd ed., ser. Series is books of Mathematics in Science and Engineering. New York, NY, USA: Academic Press, 1973, vol. 61.

[15] R. Bellman and E. S. Lee, "Functional equations in dynamic programming," Aequationes Math., vol. 17, pp. 1-18, 1978.

[16] T. Bhakta and S. Mitra, "Some existence theorems for functional equations arising in dynamic programming," J. Math. Anal. Appl., vol. 98, pp. 348-362, 1984.

[17] H. Bouhadjera and C. Godet-Thobie, "Common fixed theorems for pairs of subcompatible maps," arXiv:0906.3159v1 [math.FA], 17 June (2009)[Old version].

[18] H. Bouhadjera and C. Godet-Thobie, "Common fixed theorems for pairs of subcompatible maps," arXiv:0906.3159v1 [math.FA], 23 May (2011)[New version]. 
[19] A. Branciari, "A fixed point theorem for mappings satisfying a general contractive condition of integral type," Int. J. Math. Math. Sci., vol. 29, no. 9, pp. 531-536, 2002.

[20] S. Chauhan, H. Aydi, W. Shatanawi, and C. Vetro, "Some integral type fixed point theorems and an application to systems of functional equations," Vietnam J Math, DOI 10.1007/s10013-0130030-6, vol. 42, no. 1, pp. 17-37, 2014.

[21] S. Chauhan, Z. Kadelburg, and S. Dalal, "A common fixed point theorem in metric spaces under general contractive conditions," J. Appl. Math., vol. Article ID 510691, pp. 1-7, 2013.

[22] Y. Cho, "Fixed points for compatible mappings of type (A)," Math. Japon., vol. 18, pp. 497-508, 1993.

[23] Y. Cho, R. Saadati, and S. Wang, "Common fixed point theorems on generalized distance in ordered cone metric spaces," Comput. Math. Appl., vol. 61, pp. 1254-1260, 2011.

[24] Y. Cho, M. Shah, and N. Hussain, "Coupled fixed points of weakly $F$-contractive mappings in topological spaces," Appl. Math. Lett., vol. 24, pp. 1185-1190, 2011.

[25] Y. Cho, B. K. Sharma, and D. Sahu, "Semi-compatibility and fixed points," Math. Japon., vol. 42, no. 1, pp. 91-98, 1995.

[26] L. Ćirić, “On a family of contractive maps and fixed points," Publ. Inst. Math. (Beograd) (N.S.), vol. 17, no. 31, pp. 45-51, 1974.

[27] D. Djorić, Z. Kadelburg, and S. Radenović, "A note on occasionally weakly compatible mappings and common fixed point," Fixed Point Theory, vol. 13, no. 2, pp. 475-480, 2012.

[28] A. Djoudi and A. Aliouche, "Common fixed point theorems of gregus type for weakly compatible mappings satisfying contractive conditions of integral type," J. Math. Anal. Appl., vol. 329, no. 1, pp. 31-45, 2007.

[29] J. Fang and Y. Gao, "Common fixed point theorems under strict contractive conditions in Menger spaces," Nonlinear Anal., vol. 70, no. 1, pp. 184-193, 2009.

[30] E. Hewitt and K. Stromberg, Real and Abstract Analysis. New York: Springer-Verlag, 1965.

[31] M. Imdad, J. Ali, and M. Tanveer, "Remarks on some recent metrical common fixed point theorems," Appl. Math. Lett., vol. 24, no. 7, pp. 1165-1169, 2011.

[32] M. Imdad, S. Chauhan, Z. Kadelburg, and C. Vetro, "Fixed point theorems for non-self mappings in symmetric spaces under $\varphi$-weak contractive conditions and an application of functional equations in dynamic programming," Appl. Math. Comput., vol. 227, pp. 469-479, 2014.

[33] G. Jungck, "Compatible mappings and common fixed points," Int. J. Math. Math. Sci., vol. 9, no. 4, pp. 771-779, 1986.

[34] G. Jungck and B. Rhoades, "Fixed points for set valued functions without continuity," Indian J. Pure Appl. Math., vol. 29, no. 3, pp. 227-238, 1998.

[35] Z. Kadelburg, S. Radenović, and N. Shahzad, "A note on various classes of compatible-type pairs of mappings and common fixed point theorems," Abstract Appl. Anal., vol. Article ID 697151, pp. $1-6,2013$.

[36] J. Li, M. Fu, Z. Liu, and S. Kang, "A common fixed point theorem and its application in dynamic programming," Appl. Math. Sci., vol. 2, no. 17, pp. 829-842, 2008.

[37] Y. Liu, J. Wu, and Z. Li, "Common fixed points of single-valued and multivalued maps," Int. J. Math. Math. Sci., vol. 19, pp. 3045-3055, 2005.

[38] Z. Liu and J. S. Ume, "On properties of solutions for a class of functional equations arising in dynamic programming," J. Optim. Theory Appl., vol. 117, pp. 533-551, 2003.

[39] Z. Liu, L. Wong, K. Kim, and S. Kang, "Common fixed point theorems for contactive mappings and their applications in dynamic programming," Bull. Korean Math. Soc., vol. 45, no. 3, pp. 573-585, 2003.

[40] H. Nashine, "New fixed point theorems for mappings satisfying generalized weakly contractive condition with weaker control functions," Ann. Polonici Math., vol. 104, pp. 109-119, 2012. 
[41] R. Pant, "Common fixed points of four mappings," Bull. Calcutta Math. Soc., vol. 90, no. 4, pp. 281-286, 1998.

[42] R. Pant, "Discontinuity and fixed points," J. Math. Anal. Appl., vol. 240, no. 1, pp. 284-289, 1999.

[43] R. Pant, "Noncompatible mappings and common fixed points," Soochow J. Math., vol. 26, no. 1, pp. 29-35, 2000 .

[44] H. K. Pathak, R. López, and R. Verma, "A common fixed point theorem using implicit relation and property (E.A) in metric spaces," Filomat, vol. 21, no. 2, pp. 211-234, 2007.

[45] H. Pathak, Y. Cho, S. Kang, and B. Lee, "Fixed point theorems for compatible mappings of type (P) and applications to dynamic programming," Le Mate., vol. 50, pp. 15-33, 1995.

[46] H. Pathak and B. Fisher, "Common fixed point theorems with applications in dynamic programming," Glasnik Mate, vol. 31, pp. 321-328, 1996.

[47] B. Rhoades, "A comparison of various definitions of contractive mappings," Trans. Amer. Math. Soc., vol. 226, pp. 257-290, 1977.

[48] B. Rhoades, "Two fixed-point theorems for mappings satisfying a general contractive condition of integral type," Int. J. Math. Math. Sci., vol. 63, pp. 4007-4013, 2003.

[49] F. Rouzkard, M. Imdad, and H. Nashine, "New common fixed point theorems and invariant approximation in convex metric spaces," Bull. Belg. Math. Soc. Simon Stevin, vol. 19, pp. 311-328, 2012.

[50] B. Samet and C. Vetro, "Berinde mappings in orbitally complete metric spaces," Chaos Solitons Fractals, vol. 44, pp. 1075-1079, 2011.

[51] B. Samet and C. Vetro, "An integral version of Ćirić's fixed point theorem," Mediterr. J. Math., vol. 9, pp. 225-238, 2012.

[52] S. Sessa, "On a weak commutativity condition in fixed point considerations," Publ. Inst. Math. (Beograd) (N.S.), vol. 34, no. 46, pp. 149-153, 1982.

[53] W. Sintunavarat and P. Kumam, "Gregus-type common fixed point theorems for tangential multivalued mappings of integral type in metric spaces," Int. J. Math. Math. Sci., vol. Article ID 923458, pp. 1-12, 2011.

[54] W. Sintunavarat and P. Kumam, "Gregus type fixed points for a tangential multivalued mappings satisfying contractive conditions of integral type," J. Ineq. Appl., vol. 2011, no. 3, pp. 1-12, 2011.

[55] C. Vetro, "On branciari's theorem for weakly compatible mappings," Appl. Math. Lett., vol. 23, no. 6, pp. 700-705, 2010.

[56] C. Vetro, S. Chauhan, E. Karapinar, and W. Shatanawi, "Fixed points of weakly compatible mappings satisfying generalized $\varphi$-weak contractions," Bull. Mayasian Math. Soc., (accepted).

[57] P. Vijayaraju, B. E. Rhoades, and R. Mohanraj, "A fixed point theorem for a pair of maps satisfying a general contractive condition of integral type," Int. J. Math. Math. Sci., vol. 15, pp. 2359-2364, 2005.

\section{Author's address}

\section{H. K. Nashine}

Disha Institute of Management and Technology, Department of Mathematics, Satya Vihar, Vidhansabha-

Chandrakhuri Marg, Mandir Hasaud, Raipur-492101(Chhattisgarh), India

E-mail address: drhknashine@gmail.com 